\title{
The Non-Codified Use of Problem Structuring Methods and the Need for a Generic Constitutive Definition
}

\author{
Mike Yearworth $^{1 *}$, Leroy White $^{2}$ \\ ${ }^{I}$ Systems Centre, Faculty of Engineering, University of Bristol, BS8 1TR, UK \\ ${ }^{2}$ Department of Management, Faculty of Social Science and Law, University of Bristol, BS8 1TN, UK \\ ${ }^{*}$ Corresponding author: Tel +44-778-969-2266, Fax +44-117-331-5719, email mike.yearworth@bristol.ac.uk
}

\begin{abstract}
When we use a PSM what is it we are actually doing? An answer to this question would enable the PSM community to considerably enlarge the available source of case studies by the inclusion of examples of non-codified PSM use. We start from Checkland's own proposal for a "constitutive definition" of SSM, which originated from trying to answer the question of knowing when a claim of SSM use was legitimate. By extending this idea to a generic constitutive definition for all PSMs leads us to propose a selfconsistent labelling schema for observed phenomena arising from PSMs in action. This consists of a set of testable propositions, which, through observation of putative PSM use, can be used to assess validity of claims of PSM use. Such evidential support for the propositions as may be found in putative PSM use can then make it back into a broader axiomatic formulation of PSMs through the use of a set-theoretic approach, which enables our method to scale to large data sets. The theoretical underpinning to our work is in causal realism and middle range theory. We illustrate our approach through the analysis of three case studies drawn from engineering organisations, a rich source of possible non-codified PSM use. The combination of a method for judging cases of non-codified PSM use, sound theoretical underpinning, and scalability to large data sets, we believe leads to a demystification of PSMs and should encourage their wider use.
\end{abstract}




\section{INTRODUCTION}

"It is the Constitutive Rules which are of greater interest since they answer the stark question: What is SSM? If there are no such rules then in what sense can SSM be said to exist?" (Checkland \& Scholes, 1999, p. 285)

Our motivation for this paper is to study the use of PSMs in engineering organisations. In particular, the programmes we have access to are increasing the amount of data available to us as researchers in the field of PSMs, producing an avalanche of technical engineered artefacts within diverse contexts such as the sustainable urban environment, defence aerospace, information systems, and transport. Our thesis is that use of PSMs abounds in these engineering organisations, but evidence of their use is obscured by the absence of any formal description of how problem structuring occurs. This is the problem of so-called noncodified use of PSMs (Gregory \& Atkins, 2012; Yearworth, Dunford, York, \& Godfrey, 2012). This leads us to a more general interest in understanding PSM practice, which in turn is part of a wider project to re-interpret PSMs into an axiomatic formulation. We wish to present a set of problem structuring principles, which would fit well with not just engineering pragmatics but also provide a basis to understand PSM practice more generally. This would possibly encourage wider use of problem structuring methods in engineering with the goal of bringing PSMs back into general Systems Engineering use (Yearworth \& Edwards, 2013) and thus mirroring the origins of SSM in the failure of Systems Engineering in messy management contexts (Checkland \& Jenkins, 1974). The majority of research efforts in this area thus far have been concerned with whether PSMs work in particular circumstances and why, and not with how or for whom. However, Gregory et al, and Bell in earlier work, have reported on recent research which seeks to adress these questions in the specific case of deciding whether the DPSIR ${ }^{1}$ framework, which is widely used in environmental work, can be considered as a PSM (Bell, 2012; Gregory, Atkins, Burdon, \& Elliott, 2013). Given the need for wide participation in DPSIR modelling Gregory et al have focussed on the necessary role of boundary critique (Ulrich, 2003).

In this paper, we are not concerned with the question of evaluation of performance as in the case of e.g. (Midgley et al., 2013; Mingers \& Rosenhead, 2004; White, 2006); our focus is to find a reliable means of detecting evidence of PSM use when it has not been described as such, from which the basis to understand PSM practice can be realised.

\footnotetext{
${ }^{1}$ Driving forces, Pressures, States, Impacts, Responses
} 
The paper will proceed as follows: First our theoretical position will be outlined. We then review a number of existing frameworks and from these develop a proposal for a generic constitutive definition of PSM use. We reflect on this proposal through the analysis of three case studies of interest to both engineers and the Soft OR community. We follow this with our discussion and conclusions.

\section{Theoretical Position}

In this section, we explore our theoretical position and how this fits in with current thinking on OR theory and practice. We start with a discussion on middle range theory, causality, and introduce the idea of causal mechanisms and its potential in understanding PSM practice.

There is a burgeoning literature on the underpinning theoretical base for PSM (and OR) practice, ranging from scientific determinism to a more critical and emancipatory stance (See (Dando \& Bennett, 1981; Jackson, 1993a; Keys, 1989; Mingers, 1992; Ormerod, 1996)). Recently, it was suggested that inferences about PSM practice requires the working out of more middle range theories (and models) (Mingers, 2007; White, 2006). This aligns with a general movement in the social sciences that middle range theorizing makes more sense in avoiding the pitfalls of agency or structure explanations of social phenomena (Giddens, 1984; Merton, 1963). In particular Merton inveighed against both grand theory at one extreme, and empiricism at the other, and advanced arguments for middle range theory, which are limited and modest in scope. A preference was expressed for theories of limited generalizability, with an intermediate position implied on the macro-micro and abstract-concrete dimensions, respectively. Middle range theorizing has the potential to be general enough to be relevant across a number of settings, but limited enough in its claim of completeness. In relation to OR, it was suggested that adopting a theoretical stance with limited scope helps to explain a specific set of phenomena, as opposed to taking a stance based on a grand theory that seeks to explain phenomena at a societal level (White, 2006). Middle range theory does not refer to a specific grand narrative theory, but is rather an approach to theory construction or theorizing. Efforts to deepen our understanding of OR interventions and improve theorising on PSMs are certainly welcome. It is, therefore, unsurprising that understanding OR practice as suggested by champions of PSMs have found fertile ground in the ideas of critical realism as an example of middle range theory. To mention only a few selected examples, Mingers argues for critical realism as an underpining philosophy for OR/MS and systems, and Yearworth and White have already adopted aspects of critical realism in explicating the use of qualitative 
coding for systems dynamics modelling (Mingers, 2000; Yearworth \& White, 2013). Yet, despite this positive resonance in many corners of the discipline, most of the discussion on the subject has gravitated towards a narrow programmatic view not related to the broader scope of a causal argument. Thus, instead of deliberating on the pertinence or potential benefits of a deeper view on causation and causal explanation to guide inquiry into the practice of OR, the discussion has been pushed, perhaps inadvertently, into an arena of paradigmatic struggles where particular methodological and theoretical issues have displaced more general discussion on mechanisms. Thus, we are drawn to ideas such as critical realism and as an example of middle range theory and to Little's notion that suggests a position of causal realism as serving the basis for both an ontological notion and an explanation of PSM methodology (Little, 2011).

Our theoretical basis is the turn in social science towards causality. This has had a long history. The foundations were laid by Hume and, later, by J. S. Mill (see (Pawson, 1989) for a review). Among these, the "method of agreement" and the "method of difference" are the most important. The "method of agreement" refers to eliminating all similarities but one: if two or more instances of the phenomenon under investigation have only one circumstance in common, the circumstance in which alone all the instances agree is the cause (or effect) of the given phenomenon. By contrast, the "method of difference" establishes the absence of a common cause or effect, even if all other circumstances are identical. Both methods thus are concerned with the systematic matching and contrasting of cases in order to establish common causal relationships by eliminating all other possibilities. Both procedures are, however, somewhat extreme in the sense that they attempt to establish a single common cause, or its absence, by controlling all other possibilities and the entire environment. Therefore, we must appeal to an essential pragmatism to reflect the messiness of the context in which we are attempting to find evidence of non-codified PSM use and this entails two further principles; causal asymmetry and equifinality. Firstly, the expectation is that the patterns of attributes will exhibit different features and lead to different outcomes depending on how they are arranged. As a result, relationships need not be symmetric (Black \& Boal, 1994). This perspective has implications on our understanding on how cause-effect relationships combine to achieve outcomes. Such an argument is both attractive and important because it implies causal asymmetry (Ragin \& Strand, 2008), i.e. that causes leading to the presence of an outcome of interest may be quite different from those leading to the absence of the outcome. Secondly, the notion of causality stresses the concept of equifinality, which refers to a situation where a system can reach the same final state from 
different initial conditions and by a variety of different paths (Katz \& Kahn, 1973). It emphasises the idea that several causal paths to an outcome exist. However, these concepts of asymmetry and equifinality have not been well translated into empirical settings.

We also aim to place the concepts of causal necessity and sufficiency at the center of theory building and analysis (e.g. (Ragin, 1987, 2000)). Specifically, we suggest that causal relations in organizations practices as well as the social world more broadly are usually better understood in terms of set-theoretic relations (Ragin \& Pennings, 2005). We argue that settheoretic methods are uniquely suitable for theory building and analysis because such methods explicitly conceptualize cases as combinations of attributes and emphasize that it is these very combinations that give cases their unique nature (Ragin, 2000). We need a technique grounded in set theory that allows for detailed analysis of our cases and i) maximizes the number of comparisons that can be made across the cases under investigation (i.e. the technique is scalable), and ii) show how causal conditions contribute to an outcome in question. The approach would be suited for analysing non-codified use and test theory because it is based in an understanding of how causes combine to bring about outcomes and because it can handle significant levels of causal complexity. The technique evaluates the relationship between an outcome and all possible Boolean combinations of the casual mechanisms. For example, given an outcome set $[O]$ the judgments on the belief that $P S M \equiv \widehat{P S M}$ is true ${ }^{2}$ for a case and mechanisms sets $\left[P^{1 \ldots N}\right]$, analysis examines which combinations of the elements of $[P]$ are most likely to produce the outcome set. The approach also provides the possibility to detect necessary and sufficient conditions for certain outcomes as well as equifinal and conjunctural causation. The implementation of this approach is discussed further in $\S 9$, which shows the relationship between sets $\left[P^{1 \ldots N}\right]$ and $[O]$ using the case study data analysed in sections 7, 8 and 9. It is only through the collection of large data sets that the questions we raise can be answered, and this work sets out a welljustified approach.

\section{Figure 1 here}

\footnotetext{
${ }^{2}$ Note that throughout the text we will use normal text PSM when we mean PSM generically, and mathematical text PSM when we mean a specific PSM such as SSM, SCA, SODA etc., and $\widehat{P S M}$ when we are observing problem structuring in action that may be labelled as a PSM once the question of our belief in the truth of $\widehat{P S M} \equiv P S M$ has been decided. We show the relationship between them in Figure 1.
} 
A key way of organizing the complex webs of cause-effect relationships into coherent accounts is by means of typologies or classifications. As Doty and Glick argue, typologies are a unique form of theory building in that they are complex theories that describe the causal relationships of contextual, structural, and strategic factors, thus offering patterns that can be used to predict variance in an outcome of interest (Doty \& Glick, 1994). Typologies and classifications are theoretically attractive for a number of reasons. Because of their multidimensional nature, the causal arguments embedded in typologies acknowledge the complexity and interdependent nature of the phenomena or interventions, in which schemes frequently rest not on a single attribute but instead on the relationships and complementarities between multiple characteristics (Doty \& Glick, 1994). Typologies and classifications are furthermore helpful because they provide for multiple causal relationships by simplifying them into a few typified and easy-to-remember profiles (see (Jackson \& Keys, 1984)) inviting their use as heuristic tools for researchers and practitioners alike (Jackson, 2000).

In sum, middle range theory is an approach to theory construction or theorizing, enabling efforts to deepen our understanding of OR interventions and improve theorising on PSMs more generally. We are also drawn to a position of causal realism as serving the basis for an explanation of PSM methodology. We analyse typologies or classification since they are complex theories that describe the causal relationships of contextual, structural, and strategic factors, thus offering patterns that can be used to explore the outcomes of interest (in our case, claims for a constitutive definition of PSM practice). We return to the necessity of this approach in the discussion.

In the next section, we draw on previous attempts at a constitutive definition then from these we begin to develop our axioms.

\section{REVIEW AND METHOD}

The purpose of this section is to review previous attempts at finding an adequate codification of PSM use. There have been limited efforts. Eden and Ackerman, worried about the "purity" of PSM use and "misunderstandings" about the theoretical and practice backgrounds, argue that it is in the "similarities" between PSMs that principles can be found; if these principles were more widely understood then this would "increase the probability of more sympathetic and successful applications" (Eden \& Ackermann, 2006). This has led to a programme of work exploring the use of scripts, building on the call by Andersen, Richardson, Rouwette, and Vennix for a greater sharing of knowledge and experience in group model building (GMB) projects (Andersen \& Richardson, 1997; Andersen, Vennix, 
Richardson, \& Rouwette, 2007; Richardson \& Andersen, 1995; Vennix, 1996). Although driven by a different motivation, the desire for identifying underlying principles to PSM use aligns well with our purpose and concepts were included in our analysis described in $\S 4$. White developed a methodology for understanding PSM use where the units of analysis were the narratives and networks produced during interventions (White, 2009). Whilst White's proposal to use Actor Network Theory and Narrative Analysis as theoretical underpinnings to a coherent description of PSM methodology was very detailed in tackling difficult theory, and it does provide excellent explanatory power about what is happening when we use PSMs, it offers little towards a means of identifying non-codified PSM use when it occurs. Yet, the potential for Actor Network Theory to capture non-codified experience was mentioned. Thus, some concepts from White's analysis were included in our analysis in $\S 4$.

We review other searches for a canonical definition for a PSM starting with Checkland and Scholes' constitutive definition for SSM (Checkland \& Scholes, 1999) and from which our quote at the start of the paper was drawn. We follow this with a review of a more expansive set of constitutive definitions from (Jackson, 2000, 2003) which are positioned within the four Burrell and Morgan paradigms (Burrell \& Morgan, 1979). We then explore relevant ideas from the field of Systems Engineering (Warfield, 1995; Yearworth \& Edwards, 2013). From this review we attempt to generate a more parsimonious definition and to explore whether there is a suitable constitutive definition for PSMs in general.

\subsection{As derived from SSM}

As stated, the problem we face as researchers is one of finding an adequate formal codification for the phenomenon of PSM use so that we can begin a process of observational data collection. This problem is the same as that posed in (Checkland \& Scholes, 1999, pp. 284-289) where they tackle the epistemological task of deciding whether a claim of SSM use was legitimate; i.e. dealing with situations, usually in published work, where SSM was incorrectly claimed to have been used and thus polluting the knowledge base of known SSM cases. The primary motivation from Checkland and Scholes was to make sure that SSM was, and is, fairly evaluated. They addressed this problem by providing a constitutive definition together with an epistemology, which catalogues the language of SSM and through which statements about its use make sense. The constitutive definition of SSM takes the form of five definitional statements about SSM use, which by implication must be observed for the claim of SSM use to be valid: 
1. SSM is a structured way of thinking about a "real-world situation perceived as problematical" with the aim to bring about improvements

2. Structured thinking based on systems ideas with an explicit epistemology i.e. what is done is expressible in the terms of this epistemology (see Table 10.1 of (Checkland \& Scholes, 1999))

3. The full claim ought to refer to only instances where

a. No automatic assumption that the real world is systemic

b. Careful distinction between unreflecting involvement and conscious systems thinking and weaving between the two

c. Holons (e.g. PAS) are created in the systems thinking phase which embody the basic systems ideas

d. Holons are used to enquire into, interrogate, the real-world in order to articulate dialogue, discourse, debate about change

4. Since SSM likely to be used in different ways, interpreted differently by each user, then some conscious thought must have gone into how it was adopted for a particular situation

5. Use of SSM yields methodological lessons, extracted by conscious reflection

Whilst these definitional statements are eminently suitable for SSM detection, they beg the question of whether they would apply to other PSMs if the explicit SSM epistemology was replaced by another, or if the need for an explicit epistemology could be finessed completely. The work of Jackson in the next section provides some insight into this.

\subsection{As derived from metamethodology}

Jackson's work on Critical Systems Practice (CSP) is presented using the four Burrell and Morgan paradigms ${ }^{3}$ as an organising framework (Jackson, 2000, 2003). He provides a set of constitutive rules for a generic methodology under each paradigm. The purpose of these rules as stated by Jackson is for "guiding and identifying critical systems practice" and therefore not designed to provide a definition of what constitutes a specific systems methodology that may be employed in a problem context. CSP is in effect fulfilling the role of metamethodology. Given that Jackson intended CSP to "protect paradigm diversity and encourage critique between paradigms" the constitutive rules for CSP as metamethodology provide insight into creativity and choice of methodology. Jackson presents constitutive rules for generic systems methodologies against each paradigm (Tables 15.1 to 15.4 in (Jackson,

\footnotetext{
${ }^{3}$ Functionalist, interpretive, emancipatory and postmodern theoretical rationales.
} 
2003, pp. 308-311)). Therefore, since Jackson would situate PSMs under the interpretive stance in his System of Systems Methodologies (SoSM) (Jackson, 1993b; Jackson \& Keys, 1984) presumably the rules for a generic interpretive systems methodology (Table 15.2) would apply. It is not a surprise, therefore, that these rules are highly reminiscent of Checkland and Scholes and thus add little in insight beyond further detail. They do however answer our question about the need for an explicit epistemology. Here Jackson finesses the point by an appeal to a simple claim that the methodology "uses systems ideas as the basis for its intervention strategy and will frequently employ methods, models, tools, and techniques, which also draw on systems ideas". What these systems ideas are seems quite open in Jackson's definition.

We have chosen to present here the constitutive rules for Jackson's CSP metamethodology to provide a more general set of concepts from which to work. We have tried to capture the essence of each rule rather than the detail:

1. A structured way of thinking about improving a problem situation which understands and respects the uniqueness of each theoretical rationale and draws upon them

2. Uses a variety of creativity enhancing methods and techniques to examine the problem situation whilst ensuring it is viewed through the perspective of each theoretical rationale

3. Uses generic systems methodologies, which can be clearly related back to a theoretical rationale as a basis for intervention, and the specific rationale may change over time

4. Claims for use of generic systems methodologies according to their particular theoretical rationale, to be justified according to appropriate principles and guidelines

5. The generic systems methodologies called for in CSP will also employ methods, models, tools, and techniques which also draw on systems ideas

6. Choices in 5 will rest on appreciation of their different strengths and weaknesses discovered through action research

7. To ensure responsiveness to the complexity and heterogeneity of the problem situation attention to be placed on pluralism - client, theoretical, methodological, representational modes, and facilitation

8. Conscious thought applied to how CSP metamethodology and generic systems methodologies are adapted 
9. Each use of CSP metamethodology and generic systems methodologies should yield research findings as well as improving the problem situation

The main contribution over Checkland and Scholes is the appeal to methodological pluralism, at multiple levels, underpinned by rigorous attachment to the theoretical rationale behind specific systems methodologies and in response to the complexity and heterogeneity of the problem situation, which we return to later. Jackson's rigorous attachment to the theoretical rationales of the underlying systems-based methodologies imposes a very specific ontological framing according to the theories of social science and social change that constitute the two axes of Burrell and Morgan's framework. This is different from the turning away from an ontological commitment (Zhu, 2011) and towards the epistemic shift that is explicit in Checkland's work summarised in Table 3.1 and Figure 3.2 of (Checkland \& Holwell, 2004, pp. 56-57). However, we have returned to such an ontological commitment, but this time not to the four Burrell and Morgan paradigms but to causal realism. Of worthwhile note is that sense making at this metamethodology level also requires an essential creativity in approach.

\subsection{As derived from Systems Engineering}

Following the lead of earlier work in the Engineering Department at Cambridge University (CUED, 2011), Yearworth and Edwards attempted to find a constitutive definition for SSM referring to the set of definitional statements for SSM use as an axiomatic formulation (Yearworth \& Edwards, 2013). This was motivated by a desire to introduce engineering into the essential principles of SSM based on the belief that engineers would, pragmatically, prefer to consume this knowledge as principles or axioms rather than specific method. The definitional statements for the Yearworth/Edwards (ex CUED) formulation of SSM are as follows:

1. Problems are constructs of an individual's mind and therefore do not exist independently of human thought. These constructs are defined by an individual's "world view"; therefore it is important to look at worldviews as a basis for understanding any individual's statement of a problem,

2. The problem field is invariably messy - many potentially related problems and sub-problems can interact in any given system,

3. World views mean that different but equally valid interpretations of the real world can exist among individuals,

4. As a corollary of the first axiom - solutions to problems are also intellectual constructs and no problem exists "in isolation", 
5. Improvements and beneficial interventions in any system problem are most likely to come through sharing of "perceptions, persuasion and debate". Analysts/researchers/problem solvers should be "interactive/therapeutic, not expert", and

6. Furthermore, analysts cannot be "divorced from the problem" and they cannot act as objective "outsiders" as in engineering hard-systems research.

This formulation concentrated far more on the messiness of the problem context and invariableness of differing worldviews, thus characterising SSM as methodology concerned with both complexity and pluralism; i.e. corresponding to the middle column of Jackson's SoSM (Jackson, 1993b; Jackson \& Keys, 1984). In addition to the strong dose of subjectivity in accepting worldviews and lack of an objective standpoint from which to tackle messy problems perhaps the most challenging component is Statements 5, which is an exhortation away from expertise and towards more interactive and therapeutic approaches (see also (Taket \& White, 2000)).

Emerging from the systems science community, Warfield coined the term "spreadthink", a neologism to label the phenomenon of groups ineffectually dealing with complex issues (Warfield, 1995). We have interpreted Warfield's definition as describing the behaviour of groups dealing with problems to do with complexity and pluralism in the absence of a suitable of PSM, and therefore provides useful discrimination in our set theoretic approach. Despite the reversed logic, something akin to both the constitutive definitions and axiomatic formulation can be seen in the following definitional statements (laws in the original paper):

1. Inherent conflict; the complexity of the context entails conflict between actors,

2. Diverse beliefs; the complexity of the context means that there will be differing worldviews,

3. Limits; actors' rationality is bounded (Simon, 1991),

4. Organizational linguistics, the organizational language to supply conceptual terminology is inadequate,

5. Structural underconceptualization; actors apply non appropriate methodology to complex issues, and

6. Requisite saliency; the problem of groups getting off the point, "spurious saliency" or more simply, losing the plot.

The first two statements align well with the concept of worldviews expressed above. However, the remaining statements 3-6 flag possible inadequacies in the conceptual thinking of the participants in a structured intervention and can be used as a test - have these 
limitations been addressed in any way? They are thus a useful addition to the preceding definitions. We can therefore invert the definitional statements 3-6 into the equivalent of a constitutive definition by merely requiring evidence that the users of the putative PSM are aware of these issues and have taken appropriate steps to mitigate for them.

\subsection{Synthesis}

Based on these starting points and the problem situation, the challenge we have addressed in our work has been to establish the foundations for these two proposals:

1. A proposal for a suitable constitutive definition that is generic for all PSMs; presented as a set of testable propositions based on analysis of existing definitional statements, and a method of testing for their presence in a putative PSM intervention, and

2. A proposal for dealing with the epistemology problem, avoiding the trap that the testable propositions sit within one specific epistemology (e.g. SSM) by using Jackson's CSP metamethodology finesse that stipulates "uses systems ideas". This also includes cross referencing to an analysis of PSM review literature, which is discussed further below, and incorporation of key systems concepts into the set of testable definitional statements.

Given that the wider ambition is to theorise about PSM use we also go on to address the following issues:

1. Revisiting the structure/agency debate in the light of a strong commitment to causal realism,

2. Understanding the role that pragmatism has played when we observe non-codified PSM use,

3. Exploring the notion of expertise in PSM practice,

In addition to the foundations built on causal realism (Little, 2011), we have grounded our analysis firmly in a realist evaluative approach (Pawson \& Tilley, 1997), with reference to critical realism as described in (Mingers, 2000), and a realist approach to research methods (Sayer, 1992).

\section{TOWARDS A SET OF AXIOMS}

We take as a base for our approach key ideas from realist evaluation and causal mechanisms in the social realm (Little, 2011). Specifically, the observation that "causal outcomes follow from mechanisms acting in contexts" (Pawson \& Tilley, 1997) and the assertion that "causal connections between events and conditions are real" i.e. causal realism 
(Little, 2011). This assertion requires a credible hypothesis about the underlying causal mechanism that connects the events. In Little's words:

"A causal mechanism is (i) a particular configuration of conditions and processes that (ii) always or normally leads from one set of conditions to an outcome (iii) through the properties and powers of the events and entities in the domain of concern" (Little, 2011).

Causal realism serves the dual purpose here of both our ontological foundation and a guide to methodology.

From this base we can state that the outcomes from PSM use are a set of purposeful activities $[A]$ arising from the application of a putative $\mathrm{PSM}^{4}$, which we have labelled $\widehat{P S M}$ (the mechanism), in an appropriate context (Ormerod, 2013b) e.g. complex-plural (CP), based on Jackson's SoSM classification (Jackson, 1993b; Jackson \& Keys, 1984). Methodological choice - according to SoSM, CSP, or any other framework or metamethodology - is the intentional act of agents "socially situated in embodied social relations" and referred to as methodological localism following (Little, 2011). Thus context and choice go hand in hand.

The formulation we have stated here has similarities with the basis for evaluating PSMs in (Midgley et al., 2013), although we have decided that questions of purpose are essentially existential, and we are less concerned about why a particular intervention was initiated. In addition, as we argue later, there is an essential relationship between outcomes and purpose when evaluating PSM use, however, for identifying non-codified PSM use outcomes have little relevance and we can concentrate on mechanisms and context.

The concept of middle range theorising is crucial here. We can state that $\widehat{P S M}$ use is a middle range theory about the mechanisms that link the potential for human resources and reasoning in a $C P$ context to resolve a problem situation through a set of purposeful activities [A] (Little, 2011; Pawson \& Tilley, 1997). PSM use is a real social process, an activity that takes place above the level of isolated individual actions, but below the level of full theories of whole social systems (Merton, 1963). Again, in Little's words:

"general enough to apply across a wide range of institutional settings, but restricted enough in its claim of comprehensiveness to admit of careful empirical investigation." (Little, 2011)

\footnotetext{
${ }^{4}$ See footnote 1 and Figure 1 for a reminder of our notation.
} 
The question of whether the putative PSM is actually a PSM, i.e. whether we hold the belief that $\widehat{P S M} \equiv P S M$ is true, becomes the problem of implementing a testing process over the set of propositions $[P]$ in the observation of the use of the $\widehat{P S M}$. This happily pushes evaluation out to a subsequent question (i.e. did the PSM work?) as discussed in the introduction and thus outside the scope of this analysis. We return to the question of observation, and the role of primary and secondary data, in the analysis of the case studies. This realist formulation of the problem requires a number of concepts; the explanatory mechanism, stratified reality, the context, and regularities, which we discuss in the following sections.

\subsection{Explanatory Mechanism}

What does it mean to view a PSM as an explanatory mechanism? The PSM in use fulfils the role of an explanatory mechanism (a middle range theory) in that it formally links the problem and its context (the problem situation) to the set of purposeful activities taken to intervene in the problem situation. Therefore, using our approach we can state our middle range theory of PSM use as follows:

We can verify PSM use when we have evidence that some or all of a specific well defined set of behaviours are observed whenever a facilitated group has the task of agreeing a set of purposeful activities in order to intervene in a situation that is deemed to be problematic.

\section{2. $\quad$ Stratified Reality}

Taking a critical realist position on the explanatory mechanism provides us with a stratified view of reality, which is necessary given our focus on engineering organisations and the relationship between the artefacts of engineering and the problem contexts. For example, the following process views at different layers make the point

1. Designing a gas turbine engine to meet a certain set of requirements $\mid$ Improving Systems Engineering practices in an engineering organisation (case study 1)

2. Sizing a wind turbine for a given location $\mid$ Achieving planning approval to locate a wind farm at that location

3. Designing a vehicle shuttle wagon for the channel tunnel | Dealing with litigation arising from changes to the specification and delay in providing approval to design documents (case study 2)

4. Sizing a data centre for a required operational load | Dealing with inadequately conceived procurement processes for buying ICT services 
5. Designing a levee to withstand certain standardised storm criteria $\mid$ Deciding the National Standardised Storm Criteria (case study 3)

Each view at a different layer reveals the constant interplay between technical artefacts, which are a consequence of implementing $[A]$, and the $\widehat{P S M}$ use which gives rise to $[A]$. The case study used in $\S 5$ specifically illustrates the point (Yearworth et al., 2012). Recent work from Ormerod, based on the concept of the mangle of practice from the sociologist Andrew Pickering, seems to support this idea in that it places emphasis on the need to consider the interactions over time of the human, conceptual, and material components of a project (Ormerod, 2013a). Furthermore, Ormerod argues that authors of "technical" OR case studies rarely focus on writing about the "process" of OR to the detrement of our collective learning about practice. The essence of our approach, as we further elaborate in this section, is that it is regularities in the mechanism of PSM use, the $[P]$, that we are interested in (i.e. the process of OR in Ormerod's paper), not the technical outcomes of intervention, the $[A]$.

\subsection{Context}

The question of deciding whether the context for the $\widehat{P S M}$ use was meaningful is also important (Sayer, 1992). As a starting point, we have used Jackson's SoSM as a means of categorising context (Jackson, 1993b; Jackson \& Keys, 1984). The SoSM clearly states that the use of PSMs is appropriate in Simple-Plural $(S P)$ and Complex-Plural $(C P)$ contexts, but not in Simple-Coercive (SC) or Complex-Coercive (CC). Checkland also asserts that SSM is appropriate in 'hard' Systems Engineering contexts too (in the sense of Table 3.1 in (Checkland \& Holwell, 2004, p. 56)), i.e. also applicable to Simple-Unitary $(S U)$ and Complex-Unitary $(C U)$. Ormerod makes a similar suggestion in his proposal for Critical Rationlism in Practice (CRP) (Ormerod, 201x). Therefore, we suggest that it makes more sense that the testable propositions include determinism of context explicitly as part of the process of deciding the truth of $\widehat{P S M} \equiv P S M$. To a certain extent, the axiomatic formulation of (Yearworth \& Edwards, 2013) already does this by definitional statements that pertain to a $(C P)$ context. However, we believe that the use of the SoSM is too limiting for this to be a final determinant of context in the formulation of $[P]$. Since PSM use is a form of "organized finding out" it is likely that knowledge of the problem situation is not static but dynamic throughout the engagement (Mingers \& Rosenhead, 2004), Jackson's CSP also supports this view (Jackson, 2001), as does Ormerod in his description of the mangle of OR practice and the dynamic nature of the interplay of human, material, and conceptual components (Ormerod, 2013a). This also echoes the notion of boundary critique (Midgley, 2000, pp. 103- 
104,131-133; Ulrich, 2003) and its role in determining the context for evaluation in (Midgley et al., 2013). We have also referred to the classification schema from (Mingers, 2003) as a means of improving our definition of appropriate context for PSM use in $[P]$.

\subsection{Regularities}

If we use a PSM consistently within a given context then we might expect there to be some regularity in the outcome. Of course the difficulty we have to deal with in social science is that the presenting problem and its context, the problem situation, are almost certainly not repeatable, which means that we get a different set of purposeful activities $[A]$ every time. However, the goal of a realist explanation is to point to an explanatory mechanism that is responsible for generating the regularities we do observe in PSM use (Pawson \& Tilley, 1997). In this case, that PSM use in an appropriate context leads consistently by a process of generative causality to a set of purposeful activities (Pawson \& Tilley, 1997) i.e. PSM use is not just sufficient, it is the necessary middle range theory that links the problem situation to purposeful activities. Therefore, although it is tempting to view the purposeful activities $[A]$ as the regularity we observe as a result of applying our PSM (the explanatory mechanism), it is in fact the observation of certain problem structuring behaviours, that belong to the set of testable propositions $[P]$, that constitute the regularity. This means that when faced with a specific problem within a particular $(C P)$ context we consistently and repeatedly see some or all of $[P]$, and we can therefore completely disregard $[A]$ from any consideration.

\subsection{A generic constitutive definition}

This analysis leads us to the conclusion that to formulate a generic constitutive definition for PSMs the set $[P]$ needs to have the following properties:

1. It needs to be agnostic with respect to any specific PSM i.e. the statement $\widehat{P S M} \equiv P S M$ is considered to be true because sufficient evidence of $[P]$ has been found regardless of whether the PSM is SSM, Journeymaking (SODA), SAST, or anything else that has the same properties of a PSM e.g. the case of non-codified PSM use described in (Gregory \& Atkins, 2012), and subsequently declared as a PSM in (Gregory et al., 2013),

2. As a corollary of $1,[P]$ must be divorced from any epistemology that constrains the $\widehat{P S M}$ to be any specific, known, PSM i.e. it must allow for the pragmatic expansion of the set of possible PSMs, including ad hoc, one-off use, to be included in the data set of PSM use, 
3. As an adjunct to 2, although the epistemology must be divorced from any specific PSM language it must still include concepts relating to a structured way of thinking based on systems ideas $c f$ definition \#2 in (Checkland \& Scholes, 1999) and the constitutive rules \#3, \#4 and \#5 of CSP (Jackson, 2000, 2003). We also draw on Midgley's theory of systemic intervention, which places boundary critique, and theoretical and methodological pluralism central to action to improve (Midgley, 2000; Ulrich, 2003).

4. $[P]$ must be testable and include both propositions and any extra information that is needed to help a researcher decide if a definitional statement $P_{i}$ has in fact been observed in $\widehat{P S M}$ use. Whilst judgement is currently required on deciding how much of $[P]$ needs to be observed for the relationship $\widehat{P S M} \equiv P S M$ to be evaluated true, our set-theoretic approach enables us to use a large data set to refine our criteria and move away from judgment to a more objective assessment,

5. To avoid a separate determination of appropriate problem context e.g. that $(C P)$ pertains, the set $[P]$ must also include definitional statements that relate to context i.e. as they do in (Warfield, 1995; Yearworth \& Edwards, 2013).

In order to meet the $2^{\text {nd }}$ and $3^{\text {rd }}$ properties above we have reviewed literature about PSMs to elicit generic linguistic concepts that apply to all PSMs, not just specific ones, and ensured that systems concepts are included as well as common concepts not already included in the starting constitutive definitions. The analysis was conducted by a basic qualitative data analysis (Strauss \& Corbin, 1998) using QSR NVivo v10. The document sources used in the analysis were review articles on PSMs starting with Rosenhead's 1996 paper and working forward in time (Ackermann, 2012; Eden \& Ackermann, 2006; Keys, 2006; Mingers, 2011; Mingers \& Rosenhead, 2004, 2011; Rosenhead, 1996, 2006; White, 2009). We also included two articles (Midgley et al., 2013, and White, 2006) that explicitly address evaluation of PSMs since these also included insight into what actually constitutes a PSM. The document sources were loaded into NVivo and we then proceeded to analyse the data through a process of creating and refining codes, and looking for meaningful patterns in terms of theorising what might be a constitutive definition of PSMs. We began to exclude articles when we began to sense theoretical saturation in our analysis - we have not cited these sources. We conducted the process of memoing outside of NVivo by writing drafts of this paper concurrently with analysis. A number of top-level themes emerged from the analysis - 
1. Characteristics,

2. Contexts,

3. Evaluation,

4. Issues in use, and

5. Theoretical basis.

Of these themes, it is the Characteristics, Contexts, and Issues in Use which had the most relevance to the definition of $[P]$. We present the full coding tree of the concepts elicited from these sources in Appendix 1 (available online).

\section{The Set of Testable Propositions}

Based on the requirements presented at the end of $\S 4.5$ and the analysis of PSM literature we have presented our proposal for a generic constitutive definition of a PSM, i.e. the set $[P]$, in Table 1. 


\begin{tabular}{|c|c|c|c|}
\hline$i$ & $\boldsymbol{P}_{\boldsymbol{i}}$ & Constitutive Definition & Cross-References \\
\hline 1 & $\begin{array}{l}\text { Improvement } \\
\text { Activity }\end{array}$ & $\begin{array}{l}\text { A structured way of approaching systemic intervention has been taken, which was designed to lead } \\
\text { to improvements in a problematic real-world situation through a set of purposeful activities }\end{array}$ & $\begin{array}{l}\# 23, \# 35,53, \# 126 \\
\# 161, \# 173, \# \mathbf{3 0 3}\end{array}$ \\
\hline 2 & $\begin{array}{l}\text { Systemic } \\
\text { Approach }\end{array}$ & $\begin{array}{l}\text { The problem structuring approach used systems ideas (including boundary, hierarchy, } \\
\text { communication and control), which i) are appropriate to context, ii) theoretically adequate, and iii) } \\
\text { supported by appropriate systems modelling }\end{array}$ & $\begin{array}{l}\# 52, \# 54, \# 56, \# 126, \\
\# 160, \# \mathbf{2 0 3}, \# \mathbf{2 1 9}, \# 376\end{array}$ \\
\hline 3 & $\begin{array}{l}\text { Adaptation/ } \\
\text { Creativity }\end{array}$ & $\begin{array}{l}\text { Conscious thought and creativity must have gone into how the problem structuring approach was } \\
\text { adapted or elements combined for the particular problem situation }\end{array}$ & $\# 41, \# \mathbf{5 7}, \# \mathbf{1 0 6}$ \\
\hline 4 & $\begin{array}{l}\text { Methodological } \\
\text { Lessons }\end{array}$ & $\begin{array}{l}\text { Use of the problem structuring approach yielded methodological lessons, extracted by conscious } \\
\text { reflection }\end{array}$ & $\begin{array}{l}\# 20, \# 27, \# 41, \# 255, \\
\# 358\end{array}$ \\
\hline 5 & Worldviews & $\begin{array}{l}\text { The process of problematisation recognised that problems are construct of an individual's mind, } \\
\text { they do not exist independently of human thought. These constructs are defined by an individual's } \\
\text { "worldview", the problem structuring approach acknowledged these and worked with them }\end{array}$ & $\begin{array}{l}\# 29, \# 119, \# 120, \# 128, \\
\# 134, \# 154, \# 190, \# 224, \\
\# 238, \# 365\end{array}$ \\
\hline 6 & Messiness & $\begin{array}{l}\text { The problem context in which the problem structuring approach was used was recognised as } \\
\text { messy| wicked } \mid \text { swampy following definitions such as contained in (Ackoff, 1979, 1981; Rittel \& } \\
\text { Webber, 1973; Rosenhead, 1992; Vennix, 1999) }\end{array}$ & $\# 22, \# 24, \# 40, \# 239$ \\
\hline 7 & $\begin{array}{l}\text { Interactive/ } \\
\text { Iterative/ } \\
\text { Therapeutic }\end{array}$ & $\begin{array}{l}\text { The intervention in the problem situation has come about through sharing of "perceptions, } \\
\text { persuasion and debate" in a participative group setting using an interactive and iterative approach. } \\
\text { The facilitator or owner of the problem structuring approach adopted a stance that was } \\
\text { "interactive/therapeutic, not expert" }\end{array}$ & $\begin{array}{l}\# 16, \# 32, \# 37, \# 44, \\
\# 115, \# 161\end{array}$ \\
\hline 8 & Subjectivity & $\begin{array}{l}\text { In the approach taken it has been recognised that the stakeholders of the problem situation are not } \\
\text { "divorced from the problem" and that they could not act as objective "outsiders" as in "hard" } \\
\text { Systems Engineering }\end{array}$ & $\# 15, \# 381, \# 394$ \\
\hline 9 & Limits & $\begin{array}{l}\text { Approaches to problem structuring might unwittingly suffer from inter alia bounded rationality, } \\
\text { inadequacy of organizational language to supply adequate conceptual terminology, application of } \\
\text { non-appropriate methodology, "spurious saliency" etc. The approach used demonstrated that it dealt } \\
\text { with such conceptual limitations including building expertise in the use of problem structuring }\end{array}$ & $\begin{array}{l}\# 10, \# 34, \# 42, \# 48, \# 49 \text {, } \\
\# 73, \# 65, \# 123, \# 325\end{array}$ \\
\hline
\end{tabular}

Table 1. The set of testable propositions to evaluate belief in the truth of $\widehat{P S M} \equiv P S M$. The numbers in the cross-references column refer to the category code numbers in Appendix 1 (available online), which in turn reference the original source documents. These category codes are at the highest relevant level and include all sub-categories too - codes with sub-categories are shown in bold. 
The Cross-References column refers to the category code numbers from the NVivo coding tree produced from the analysis described in $\S 4.5$ above and as shown in Appendix 1 (available online). These category codes are at the highest relevant level and are meant to include all sub-categories too. For example, category code \#10 refers to the concept <as opposed to standard OR methods> and Appendix 1 (available online) shows the subcategories associated with this concept, such as <managerialism>, <mathematically sophisticated but contextually naïve> etc. As another example, category code \#73 is the concept <Drawbacks>, as a characteristic of PSMs, and contains 32 sub-categories, all of which refer to different limitations facing PSM practitioners. Not all of these sub-categories are conceptual limits - e.g. categories 88 and 93 refer to problem of lack of recognition of PSMs in the US academic community - and illustrate the need for interactivity in working with the NVivo data. Our set-theoretic approach requires that the decision making process cross-references to these categories to ensure that full consideration of the element $P_{i}$ has been seen in the putative PSM use, $\widehat{P S M}$. Ideally Appendix 1 (available online) should also include the link to the original source material from which the codes were derived, as the coding tree does in NVivo. Whilst access to NVivo enables the authors to quickly search for the original text to clarify understanding of a category during the process of determining the veracity of $P S M \equiv \widehat{P S M}$ other researchers will struggle to use the results in the same way. For this reason the NVivo project file is available from the authors on request.

Below we explore the axioms in relation to a number of case studies. Cases can be understood as theoretical constructs or as empirical units, and their relationship to the underlying phenomena may be conceptualised in a formative or reflective way. Rather than attempting a formal definition of a case here, we focus on the underlying aspect of cases that is most relevant to the questions at hand, namely the process of delimiting the real world phenomena of interest within time and space. Thus, one has to be able to identify and delimit the case from the multitude of phenomena and aspects that will not be studied.

The process of delimiting is necessary because it goes along with a contextual understanding of cases, which holds that a case combines certain characteristics or features that appear together within it and give the case its essential character. Thus, cases come swathed in theories (Weick, 2007). Also, much of the social world comes to us in lumpy form, and often the boundaries of a case will be intuitively plausible and useful due to social convention (e.g. an organisation, a subunit, a team). Thus, the process of delimiting is an essential part of the normal conduct of social science research. 
Because the case studies approach aims to maintain the holistic nature of the case or cases, it is not limited to any particular form of evidence or data collection, and it can involve single or multiple cases, various methods of data collection and several types and levels of analysis (Eisenhardt, 1989). In fact, combining evidence from multiple sources, such as interviews, archival data, and surveys frequently leads to the most successful case studies. Finally, The case studies tend to be comparative in nature, if only in the way in which observations from a case may inform knowledge about organisations and interventions in them. The case-study approach is thus more dynamic in nature, and the researchers will constantly compare theory and data in order to achieve a fit between both (Eisenhardt, 1989; Ormerod, 2013a).

\section{Case Study 1 - Gas Turbine Engine Modification}

This case study presents the re-design of a structural element within a gas turbine engine as an example of a problem from an engineering organisation that sits within a $(C P)$ context and where the re-design is the actual set of purposeful activities that are carried out to resolve the problem. The case was originally presented in 2012 at the European OR conference (Yearworth et al., 2012). Since this case is an example of the situation we wish to research, the PSM use is explicitly non-codified, i.e. we are dealing with $\widehat{P S M}$, and the problem for the researchers is to decide the truth of $\widehat{P S M} \equiv P S M$.

When originally presented (Yearworth et al., 2012), the case study focussed on the specific problem of deciding whether the $\widehat{P S M}$ corresponded to SSM by attempting to reconstruct a root definition. The main assumption made in the analysis was that a gas turbine engine (the engineering artefact), together with its design, manufacture, and maintenance constituted the boundary of our interest, and is manifested commercially as the whole-life cost of the engine. It could thus be considered as a $(C P)$ context and a fruitful place to look for $\widehat{P S M}$ data. We identified the following issues as additional sources of evidence that the context was indeed $(C P)$ :

1. Highly interconnected and interdependent engineering components,

2. Contested purpose - conflicted at multiple levels,

3. Deep expertise - origin of worldviews,

4. Ambiguity - lack of clarity about customer needs, and

5. Cutting-edge engineering, ahead of the science, operating empirically and experientially.

We list the actors involved in the use of the $\widehat{P S M}$ in Table 2. 


\begin{tabular}{|l|l|}
\hline \multicolumn{1}{|c|}{ Actor } & \multicolumn{1}{|c|}{ Role } \\
\hline \hline Chief Project Engineer & Representing the customer viewpoint \\
\hline Programme Engineer & $\begin{array}{l}\text { Responsible for deciding whether delivery to overall } \\
\text { cost and schedule can be achieved }\end{array}$ \\
\hline Design Engineer & $\begin{array}{l}\text { Responsible for producing drawings for } \\
\text { manufacturing }\end{array}$ \\
\hline Performance Engineers & $\begin{array}{l}\text { Representing appropriate aero, thermal, mechanical, } \\
\text { electrical... expertise }\end{array}$ \\
\hline Manufacturing Engineer & $\begin{array}{l}\text { Providing input on questions about how to make any } \\
\text { required components, or whether it is possible to } \\
\text { make them. Also resolving issues about volume, } \\
\text { supplier capabilities, and protecting IP }\end{array}$ \\
\hline Cost Engineer & $\begin{array}{l}\text { Able to supply estimates of manufacturing costs and } \\
\text { supply chain issues }\end{array}$ \\
\hline Development Engineer & Responsible for the verification process \\
\hline Project System Engineer & $\begin{array}{l}\text { Facilitates the process of bringing all the engineering } \\
\text { competencies listed above together in a process of } \\
\text { problem structuring to resolve the situation }\end{array}$ \\
\hline
\end{tabular}

Table 2. The actors involved in the use of the putative PSM.

We can describe this as a system owned by Rolls-Royce that was brought into existence in order to reduce whole-life cost by a focussed re-design of an essential engine component whilst keeping within the performance constraints defined by the customer. The CATWOE derived from the case study was as follows:

- Customers - Rolls-Royce

- Actors - engineering roles identified in Table 2

- Transformation - more profitable business by reducing whole-life cost

- Weltanschauung - an engineering-led solution to the transformation exists

- Owner - development function operating review gates on the re-design

- Environmental Constraints - performance (weight, fuel burn, thrust, noise...), laws of physics, current engineering practice, budget, schedule

The case study at this stage (Yearworth et al., 2012) demonstrated some evidence that the statement $\widehat{P S M} \equiv P S M$ is true, at least for the narrow question of whether the PSM is SSM. 
The case is now further analysed in Table 3 against the set of propositions $[P]$ to show how we have applied the testing mechanism.

\begin{tabular}{|c|c|c|c|}
\hline$i$ & $\boldsymbol{P}_{\boldsymbol{i}}$ & Observed & Analysis \\
\hline 1 & $\begin{array}{l}\text { Improvement } \\
\text { Activity }\end{array}$ & Yes & $\begin{array}{l}\text { A structured approach was taken to the Front Bearing Housing } \\
\text { Support Re-Design problem. Problematization was the need for } \\
\text { a reduction in unit cost through a simplified manufacturing } \\
\text { process given the functionality desired from the component in } \\
\text { order to meet the overall whole-life cost target. }\end{array}$ \\
\hline 2 & $\begin{array}{l}\text { Systemic } \\
\text { Approach }\end{array}$ & Yes & $\begin{array}{l}\text { Interdependence between sub-system elements was modelled } \\
\text { using conventional systems engineering techniques (systems } \\
\text { context diagram, functional viewpoint diagram). This was 'hard' } \\
\text { systems modelling in the sense of Table } 3.1 \text { (Checkland \& } \\
\text { Holwell, 2004, p. 56) }\end{array}$ \\
\hline 3 & $\begin{array}{l}\text { Adaptation/ } \\
\text { Creativity }\end{array}$ & Probably & $\begin{array}{l}\text { There seemed to be some amount of "reverse engineering" } \\
\text { required in order to undo what had been done already reflecting } \\
\text { a need to achieve "Stripping back to key elements". }\end{array}$ \\
\hline 4 & $\begin{array}{l}\text { Methodological } \\
\text { Lessons }\end{array}$ & Probably & $\begin{array}{l}\text { Within the organisation there is a constant reflection on how } \\
\text { tools and techniques are working, e.g. (Parsley, York, Dunford, } \\
\& \text { Yearworth, 2013). A reflection was carried out at the end of } \\
\text { the process. One key-learning point was the need to get around } \\
\text { risk-adverse nature of design, and the problem of "read-across } \\
\text { constraints" from previous designs. }\end{array}$ \\
\hline 5 & Worldviews & Yes & $\begin{array}{l}\text { Based on experience of working with teams of this kind the roles } \\
\text { of stakeholders present suggest that the actors' worldviews } \\
\text { would be sufficiently diverse/conflicted to be consistent with a } \\
C P \text { problem situation. }\end{array}$ \\
\hline 6 & Messiness & Yes & $\begin{array}{l}\text { Given that the problem originated from whole-life cost drivers } \\
\text { it is reasonable to view this as a messy problem, not one that } \\
\text { could be 'solved' through a conventional Systems Engineering } \\
\text { technique e.g. it was not possible to find an optimal solution } \\
\text { using MCDA and this sort of thinking was not applied. }\end{array}$ \\
\hline 7 & $\begin{array}{l}\text { Interactive/ } \\
\text { Iterative/ } \\
\text { Therapeutic }\end{array}$ & Yes & $\begin{array}{l}\text { There was no right or optimal answer to this problem but a } \\
\text { compromise based on trade-offs was achieved through debate } \\
\text { and consensus in a facilitated workshop. The PSE led the } \\
\text { intervention but was not providing domain expertise or solution } \\
\text { ideas. }\end{array}$ \\
\hline 8 & Subjectivity & Probably & $\begin{array}{l}\text { The stakeholders listed in Table } 2 \text { do not sit outside the } \\
\text { organisation. Their reputational capital within the organisation } \\
\text { and rewards (company incentives) suggest that positions taken } \\
\text { in the workshops would lead to subjective positions being taken. } \\
\text { Had the approach failed there would have been reputation risk to } \\
\text { the PSE. }\end{array}$ \\
\hline 9 & Limits & No & $\begin{array}{l}\text { The team recognised in the end that they could not control the } \\
\text { interfaces to their design, and opportunity for innovation was } \\
\text { constrained. Conceptual thinking was constrained by previous } \\
\text { experience - the read-across constraints mentioned in } \\
\text { methodological lessons. }\end{array}$ \\
\hline
\end{tabular}

Table 3. The use of $[P]$ to decide the belief in the truth of $\widehat{P S M} \equiv P S M$. The example case of non-codified PSM use from this engineering organisation has been determined as True. 


\section{Case Study 2 - Design Changes and Delays on Engineering Project Costs}

The Bombardier case study has been widely cited in the literature (Ackermann, Eden, \& Williams, 1997; Mingers \& Rosenhead, 2004; Williams, Eden, Ackermann, \& Tait, 1995) and is thus reasonably well known in the PSM community. Like case study 1 it represents another project where an engineered artefact was the ostensible output, in this case a specialized rail vehicle to transport motor vehicles through the Channel Tunnel, but the complex problem context led to significant delay and disruption in the design process, and subsequent litigation by the engineering organisation, Bombardier, against its clients. The substantive core of the legal claim related to cost overruns arising from design changes, which bears strong parallels with case study 1 in that customer/client originating design changes have significant impact on business profitability for engineering organisations. The case study describes the use of cognitive mapping and systems dynamics modelling to support the legal case, in effect using the models to categorise the dynamics of the situation in order to assess the impact of the delays on the design process. The authors of the case study (Ackermann et al., 1997; Williams et al., 1995) represent the modelling expertise called in by Bombardier to support their legal action.

The presentation of the case is implicitly from within the PSM community, as determined by authors' publication record, and to the PSM community, as suggested by target journal in the case of (Williams et al., 1995). There is little doubt therefore, that the combination of modelling techniques in the approach to problem structuring and the problem context itself would suggest anything other than the fact that, despite no explicit claim to PSM use in (Williams et al., 1995), we should be confident in asserting that $\widehat{P S M} \equiv P S M$ is true. We therefore use this case study to reflect on the veracity of the testable propositions $[P]$ we have developed. The analysis is presented in Table 4 and our discussion follows below.

\begin{tabular}{|c|l|l|l|}
\hline $\boldsymbol{i}$ & \multicolumn{1}{|c|}{$\boldsymbol{P}_{\boldsymbol{i}}$} & Observed & \multicolumn{1}{c|}{ Analysis } \\
\hline 1 & Improvement Activity & Yes & $\begin{array}{l}\text { A structured approach is clearly described in } \\
\text { (Ackermann et al., 1997). The improvement } \\
\text { intervention is clearly one of improving the position of } \\
\text { the clients in justifying their claims for substantial } \\
\text { damages in a court case. }\end{array}$ \\
\hline 2 & Systemic Approach & Yes & $\begin{array}{l}\text { The use of cognitive mapping to produce influence } \\
\text { diagrams and system dynamics modelling - "model } \\
\text { was developed and validated... with groups of senior } \\
\text { members of the project team" (Williams et al., 1995) - } \\
\text { definitely indicates a systemic approach was taken. }\end{array}$ \\
\hline 3 & $\begin{array}{l}\text { Adaptation/ } \\
\text { Creativity }\end{array}$ & Yes & $\begin{array}{l}\text { The approach taken mixed different methods into a } \\
\text { multimethodology, and specifically modified a standard } \\
\text { PSM approach (SODA) to meet the needs of this } \\
\text { specific intervention. }\end{array}$ \\
\hline
\end{tabular}




\begin{tabular}{|c|c|c|c|}
\hline 4 & $\begin{array}{l}\text { Methodological } \\
\text { Lessons }\end{array}$ & Yes & $\begin{array}{l}\text { Although not laboured in (Ackermann et al., 1997) the } \\
\text { significant methodological reflections were focussed on } \\
\text { the benefits of integrating 'hard' and 'soft' methods in } \\
\text { the sense of (Checkland \& Holwell, 2004). Further } \\
\text { methodological lessons were drawn concerning the } \\
\text { richness of the data available that ensued from the } \\
\text { mixed-methods approach. The benefits of cycling } \\
\text { between modelling approaches was also flagged. }\end{array}$ \\
\hline 5 & Worldviews & Yes & $\begin{array}{l}\text { "views of corporate managers often differed from those } \\
\text { of plant managers...verbal reports seemed to contradict } \\
\text { much of the hard data" (Ackermann et al., 1997) }\end{array}$ \\
\hline 6 & Messiness & Yes & $\begin{array}{l}\text { The problem context is undoubtedly messy, the case } \\
\text { originates from litigation }\end{array}$ \\
\hline 7 & $\begin{array}{l}\text { Interactive/ } \\
\text { Iterative/ } \\
\text { Therapeutic }\end{array}$ & & $\begin{array}{l}\text { Although there seemed no one coherent lead in } \\
\text { facilitating interaction with stakeholders the process } \\
\text { was undoubtedly interactive and iterative. Evidence of a } \\
\text { cyclical approach is shown clearly in (Ackermann et al., } \\
\text { 1997, p. Figure 1) }\end{array}$ \\
\hline 8 & Subjectivity & $\mathrm{X}$ & The case was unclear on this point. \\
\hline 9 & Limits & Yes & $\begin{array}{l}\text { The choice and application of the systemic approaches } \\
\text { described in the papers reflects the deep PSM expertise } \\
\text { of the authors. There is no evidence to suggest that the } \\
\text { team failed to deal with conceptual limitations. }\end{array}$ \\
\hline
\end{tabular}

Table 4. The use of $[P]$ to decide the truth of $\widehat{P S M} \equiv P S M$ for case study 2 . In our judgement, PSM use by the engineering organisation in this case has been determined to be True.

The JORS paper (Williams et al., 1995) focuses on presenting numerical results from the system dynamics model and implications for the network planning of projects. The significant reflections in the paper say nothing about methodological lessons learned $\left(P_{4}\right)$, interactivity/therapeutic skills $\left(P_{7}\right)$, subjectivity $\left(P_{8}\right)$, or limits $\left(P_{9}\right)$. The implications of this work are focussed on network planning and not back on the methods used. The System Dynamics modelling was essentially positivistic and functionalist, and designed to provide numerical predictions that would be tested for "validity" by the appellants in the case. It was considered to be a "forensic model" that had to "demonstrate the same general patterns of behavior as the real system" (Ackermann et al., 1997). Taken by itself, the case as described in the JORS paper would not be viewed as a PSM in use. However, the Interfaces paper (Ackermann et al., 1997) describes the interaction between the System Dynamics modelling and the other systems modelling approaches within the overall approach adopted with the clients. Our conclusion based more on this source is that the definitions in $[P]$ were sufficient to discriminate between a report of a fairly conventional use of System Dynamics modelling and the overall problem structuring approach that used the results of this modelling; the former was not evidence of PSM use, but the latter was. 


\section{Case Study 3 - New Orleans Storm Surge Protection}

Our third case study is more speculative and is derived from an original claim by Little that the

"...breaking of the Levees in new Orleans was the result of circumstances that included both natural and social components - the occurrence of the storm but also the institutional breakdown of the Army Corp of Engineering that had led to the poor condition of the levees in 2005" (Little, 2011).

Whilst general knowledge of the disaster provides ample evidence that this was no doubt a wicked problem we still need some point of intervention located in the time leading up to the failure of the levees on the $29^{\text {th }}$ August, and beyond into the subsequent events arising from the 53 breaches that occurred as the Hurricane Katrina storm surge hit New Orleans, in which to locate our analysis. A literature review revealed the existence of a legal case in 1976 that led to an injunction against the Army Corp of Engineering's hurricane protection system project for New Orleans (Kysar \& McGarity, 2006). Speculation had arisen after the hurricane that this earlier environmental lawsuit had in some sense caused the destruction of New Orleans in 2005 - the "lawsuit that drowned New Orleans". Whilst the conclusion from the analysis by Kysar and McGarity dismisses the injunction as not causally relevant to the disaster, they do provide a useful history of the "decision processes that eventuated in the New Orleans storm surge protection system" as they existed at the time of the hurricane. It is this sequence of decision processes presented in the history that we consider as our putative PSM. Further supporting data are gleaned from i) a realist, engineering perspective on the failure of the levees and what might have been done to improve them (Sattar, Kassem, \& Chaudhry, 2008), ii) analysis from a sociologist who considers the unfolding disaster from the perspective of a number world views (war zone, tragedy, crime scene, anarchy...) (Miller, 2012), and iii) a report from the National Hurricane Centre in the USA (Knabb, Rhome, \& Brown, 2005). We present our analysis in Table 5 and our discussion below.

\begin{tabular}{|l|l|l|l|}
\hline $\boldsymbol{i}$ & \multicolumn{1}{|c|}{$\boldsymbol{P}_{\boldsymbol{i}}$} & Observed & \multicolumn{1}{c|}{ Analysis } \\
\hline \hline 1 & Improvement Activity & No & $\begin{array}{l}\text { There was no specific identifiable systemic } \\
\text { intervention that could be used for analysis as the data } \\
\text { sources gave broad time histories of the events leading } \\
\text { up to the Katrina disaster. This illustrates the need for } \\
\text { access to primary data. }\end{array}$ \\
\hline 2 & Systemic Approach & No & $\begin{array}{l}\text { There was no evidence in any of the sources analysed } \\
\text { that a systemic approach, at any time, was used. }\end{array}$ \\
\hline 3 & $\begin{array}{l}\text { Adaptation/ } \\
\text { Creativity }\end{array}$ & No & No evidence. \\
\hline 4 & $\begin{array}{l}\text { Methodological } \\
\text { Lessons }\end{array}$ & Yes & $\begin{array}{l}\text { "What often will be required... is collective judgement } \\
\text { regarding the degree of moral and political }\end{array}$ \\
\hline
\end{tabular}




\begin{tabular}{|c|c|c|c|}
\hline & & & $\begin{array}{l}\text { commitment that citizens desire to express, both to } \\
\text { their fellow citizens within the present generation and } \\
\text { to the generations to come, through public prevention } \\
\text { and mitigation projects that may have highly uncertain } \\
\text { long-term payoffs...through familiar tools of risk } \\
\text { assessment and policy analysis the planning process } \\
\text { seems to have inadvertently obscured the need for } \\
\text { precisely that brand of judgment" (Kysar \& McGarity, } \\
\text { 2006). There is further analysis in (ibid) pointing out } \\
\text { deficiencies in the "murky blending of science and } \\
\text { policy" in the revisions to the Standard Project } \\
\text { Hurricane (SPH) technical model in 1979, used by the } \\
\text { Army Corp of Engineers as a requirement } \\
\text { specification for design of hurricane protection } \\
\text { measures. However, although this reflection has taken } \\
\text { place it is unclear what impact it has had in decision } \\
\text { making in the on-going problem context. Have these } \\
\text { process lessons been learned? }\end{array}$ \\
\hline 5 & Worldviews & No & $\begin{array}{l}\text { The stakeholders involved - Congress, Army Corp } \\
\text { leaders and staff, local residents and officials, } \\
\text { scientific and engineering experts, government } \\
\text { contractors, local and national political interests - } \\
\text { represent a vast range of possible worldviews (Kysar } \\
\& \text { McGarity, 2006). However, there was no evidence } \\
\text { that these were acknowledged or worked with in any } \\
\text { meaningful way. }\end{array}$ \\
\hline 6 & Messiness & Yes & $\begin{array}{l}\text { The problem context was undoubtedly wicked, which } \\
\text { once Katrina struck led to "a wide swath of } \\
\text { catastrophic damage and inflicted large loss of life." } \\
\text { (Knabb et al., 2005) "the systems that drive the } \\
\text { incidence and severity of disaster consequences... are } \\
\text { characterized by enormous complexity and } \\
\text { uncertainty" (Kysar \& McGarity, 2006) }\end{array}$ \\
\hline 7 & $\begin{array}{l}\text { Interactive/ } \\
\text { Iterative/ } \\
\text { Therapeutic }\end{array}$ & No & $\begin{array}{l}\text { The quote in row } 4 \text { above suggests there was a failure } \\
\text { to do this over the years. }\end{array}$ \\
\hline 8 & Subjectivity & No & $\begin{array}{l}\text { The analysis in (Kysar \& McGarity, 2006) focused on } \\
\text { the complexity of the modelling task to better predict } \\
\text { performance of the flood defences. The techniques } \\
\text { discussed are undoubtedly functionalist and realist and } \\
\text { suggest a dogged objectivity - a "normative } \\
\text { reification" of the SPH technical model (ibid) }\end{array}$ \\
\hline 9 & Limits & No & $\begin{array}{l}\text { The Corp of Engineers view of the problem context } \\
\text { and interventions seems to have dominated leading to } \\
\text { the impression of structural under-conceptualisation } \\
\text { and inadequate organisational linguistics. The } \\
\text { quotation in the introduction to (ibid) says "There are } \\
\text { only two kinds of levees, those that have failed and } \\
\text { those that will fail". Spreadthink seems to have } \\
\text { blinded the Corp of Engineers to this homily. }\end{array}$ \\
\hline
\end{tabular}

Table 5. The use of $[P]$ to assess the truth of $\widehat{P S M} \equiv P S M$ for case study 3. In our judgement, PSM use in the decision processes that eventuated in the New Orleans storm surge protection system has been deemed False. 
Our framework fails to identify the on-going processes behind the construction of the New Orleans levees as a PSM, i.e. we believe $\widehat{P S M} \equiv P S M$ to be false. This is not surprising. Our framework has been designed with an organisational setting in mind and around a specific point of intervention. Whilst in this case the problem context is undoubtedly a complex social setting and involves an engineering organisation in the on-going maintenance and construction of levees as the engineering artefact. Unlike the previous case studies the decision making process extended over a considerable period of time with no one intervention standing out as leading to a set of outcomes that changed the course of events; the 1970s lawsuit having already been dismissed as not causally relevant.

However, our analysis here is somewhat limited and a far more in-depth investigation of some of the planning events that led to specific protection initiatives being undertaken, e.g. the "High Level" and the "Barrier" option considerations post Hurricane Betsy in 1965, would be required. Our experience of trying to analyse this case has revealed the difficulty of obtaining data about processes and behaviours, the $[P]$, when the historical record is primarily concerned with the outcomes of decisions, the $[A]$, i.e. what was actually built and what failed. This suggests that for our framework to be useful, researchers using it require access to primary data, e.g. through interviewing the stakeholders involved in decision making, rather than using the historical record in reports or academic texts. Although on the specific point of methodological lessons learned, $P_{4}$, there is some clarity in (Kysar \& McGarity, 2006) and thus primary data may not always be required to learn the lessons from failure.

Although the conclusion from our, albeit limited, analysis was that we could find no evidence of PSM use, the lingering doubt about detection arising from inadequate access to data means that questions about PSM evaluation, as a consequent action to PSM detection, are rarely likely to be clear cut. In the case of the levee failures when Katrina struck we can be categorical that PSMs were never in the "dock" (Ackermann, 2012). Would a similar conclusion be obtained in the case of other high cost failures e.g. the UK National Programme for IT in the NHS procurement (House of Commons Committee of Public Accounts, 2013)?

Another concern is the question of context. Despite the initial reference to the SoSM and use of the SP/CP contexts as relevant for PSM use, our framework relies on judgement of the messiness of a problem context and evidence that it is at least not unitary (SU/CU). However, in the case of the levee failure in New Orleans power structures undoubtedly played a role in 
the decision making processes that took place in the years running up to the disaster. In which case PSMs would have been inadequate in this situation (Midgley, 1997; Ulrich, 2003; Ulrich $\&$ Reynolds, 2010). The recent work from Gregory et al in the use of the DPSIR framework points towards a PSM that is perhaps more appropriate in this context. Had PSMs been in the dock in this case, would evaluation subsequently have decided that they had been used inappropriately? We can only speculate here, but it is clearly an area for further work as move into analysis of larger data sets rather than the limited case studies here.

\section{Scaling the Method to Large Data Sets}

The three case studies analysed provide the starting data set for the much more ambitious task of using the set theoretic approach we outlined in $\$ 2$ to scale the method to very large data sets in order to improve the quality of our set $[\mathrm{P}]$ for use in the task of detecting noncodified PSM use. The initial data for analysis are laid out in Table 6.

\begin{tabular}{|c|c|c|c|c|c|c|c|c|c|c|c|}
\hline$[\boldsymbol{P}]$ & $P_{1}$ & $P_{2}$ & $P_{3}$ & $P_{4}$ & $P_{5}$ & $P_{6}$ & $P_{7}$ & $P_{8}$ & $P_{9}$ & $\begin{array}{c}\text { Judgement of } \\
\widehat{P S M} \equiv P S M \text { i.e. } \\
\text { outcome set }[O]\end{array}$ & Notes \\
\hline$P^{1}$ & 1 & 1 & PT & PT & 1 & 1 & 1 & PT & 0 & PT & PT - Probably True \\
\hline$P^{2}$ & 1 & 1 & 1 & 1 & 1 & 1 & 1 & $\mathrm{X}$ & 1 & 1 & $\mathrm{X}$ - Unknown \\
\hline$P^{3}$ & 0 & 0 & 0 & 1 & 0 & 1 & 0 & 0 & 0 & 0 & \\
\hline$\cdots$ & & & & & & & & & & & \\
\hline$P^{N}$ & 0 & 0 & 0 & 0 & 0 & 0 & 0 & 0 & 0 & 0 & Added for completeness \\
\hline
\end{tabular}

Table 6. Beginnings of the truth table to scale the method to large data sets ( $1=$ True $\mid$ Yes, $0=$ False $\mid$ No). Note the addition of Row $\mathbf{N}$ to capture the perfect rejection of $\widehat{P S M} \equiv P S M$ and that the second case study was the perfect acceptance of the truth of $\widehat{P S M} \equiv P S M$. Note that the method extends to fuzzy sets by the inclusion of "don't know" values shown as $X$, and the possible fuzzification of the judgments as in case 1

\section{which uses PT (Probably True)}

This table illustrates the first stages in building the truth table for a large data set, which is required in order to scale the method we describe. Note that the addition of Row N captures the perfect rejection of the belief that $\widehat{P S M} \equiv P S M$ and that the second case study was the perfect acceptance in the belief that $\widehat{P S M} \equiv P S M$ was true. The method extends to fuzzy sets by the inclusion of "don't know" values shown as X, and the possible fuzzification of the variables and the judgment itself i.e. we have used "Probably True", but a confidence 
estimate expressed as a percentage could have been used too, or even extended to use interval probabilities (Hall, Blockley, \& Davis, 1998). In this way the contribution of $P_{i}$ to the overall judgment process of evaluating belief that $\widehat{P S M} \equiv P S M$ can be assessed. Likewise new $P_{i}$ can be added and existing ones rejected. Analysis of more case studies like Case 2, by making use of published case studies from established practitioners in the Soft OR community e.g. (Ormerod, 2005), do not add to our knowledge of what makes a PSM, unless we are considering new $P_{i}$ (and the case studies refereed to in (Ormerod, 2005) are yet to be analysed for such), it is actually the fuzzy cases that help improve our knowledge in how to spot non-codified PSM use. We would welcome communication with fellow researchers willing to contribute further rows to the data set, or indeed provide suggestions for new $P_{i}$.

\section{Discussion}

The proposed constitutive definition for PSMs developed in $\S 4,5$ and the analysis in the case studies in $\$ 6,7,8$ lead us to reflect on a number of questions about of non-codified PSM use. Our reflections concern i) the practical problem of a means for pre-screening an organisation for discovering cases of possible PSM use prior to full use of our framework, ii) exploring the notion of expertise in PSM practice, iii) understanding the role that pragmatism has played when we observe non-codified PSM use, and iv) revisiting the structure/agency debate in the light of our strong commitment to causal realism.

\subsection{Pre-screening}

We have concerns about the practical steps needed to deploy the framework in searching out examples of non-codified PSM use as candidates for future analysis. From the regularity view developed in $\S 4$ we make use here of an alternative conceptualisation of a PSM from the systems science community. We use the notion of a Problem Suppression System (PSS) articulated by (Ring, 1998). In this schema, the PSS constantly acts to make the problem "go away", a cybernetic theory control-system view of the PSS as a means of nulling the error signal (the problem). The reason it is interesting here is that we have removed from consideration the purposeful activities $[A]$ as a sign of regularity, but have instead asserted that it is the testable propositions $[P]$ that are important. Since we can reduce these to a list of problem structuring behaviours by removing the systemic epistemology and problem-context propositions i.e. the sub-set $\left[P^{\prime}\right]=[$ Improvement Activity, Adaptation/Creativity, Methodological Lessons, Worldviews, Interactive/Iterative/Therapeutic, Subjectivity, Limits], we have a ready made set of behaviours to look for in a PSS. The point is that we 
can view the PSS as co-aligned with the notion of an organisational unit, such as the redesign team in the case study \#1, which exhibits PSM use behaviours. This suggests that we can first go and look for evidence of PSSs in an organisation by conducting surveys looking for the behaviours $\left[P^{\prime}\right]$. Having identified PSSs we can then conduct detailed analysis over $[P]$ to make a determination of the truth of $\widehat{P S M} \equiv P S M$ for each example we find.

\subsection{Expertise}

The second question arising from our analysis also sheds light on a debate in engineering organisations relating to the role of the Systems Engineer (the PSE in case study \#1). We have concluded that we have observed the use of a non-codified PSM in this case study based on the propositions $[P]$ we have developed i.e. our judgement is that the statement $\widehat{P S M} \equiv P S M$ is true. Based on this determination do we conclude that since the individual PSE was not using a recognised PSM did the PSE have some sort of natural gift for problem structuring? Is the Systems Engineer an exemplar of what some people would call a systems thinker? We leave this question open since there is little evidence in the literature for any formal or agreed definition of the term and therefore how to identify it; see for example (Buckle-Henning, Wilmshurst, \& Yearworth, 2012; Cabrera, Colosi, \& Lobdell, 2008; Henning \& Chen, 2012; Sterman, 2002).

On the other hand, is there something about the availability of tools, processes, or culture within the organisation that led the Systems Engineer towards adopting a problem structuring approach that is recognisably a PSM? In this case, this was probably true - see for example (Parsley et al., 2013). The question is vexing because this cuts to the heart of a strategic question in engineering organisations; do we devote effort to finding candidate System Engineers with the right mental attributes for the job, some sort of problem structuring preference or thinking style, or do we put effort into training candidate System Engineers in the use of PSMs? Alternatively, and more bluntly, do we recommend that engineering organisations engage in profiling, especially in recruitment? Of course, this dichotomises the possible answer and in reality it is likely to be a mixture of both i.e. train those with a demonstrated tendency (or preference) towards problem structuring behaviours; although this still begs the question of how to identify them. Keys offers some clarity here; he argues that achieving expertise in PSM use is a learning activity based on a "complex process of knowledge acquisition" in progressing from novice status through many client engagements (Keys, 2006); there is no mention of any shortcut to expertise through possessing innate thinking styles. Ormerod has developed a competency model of PSM use underpinned by the 
resource based view and consisting of three broad competencies - conducting analysis, designing and managing process, and appreciating context (Ormerod, 2013b). His analysis on how soft OR skills are developed is relevant to our discussion. His personal view is that practioners emerging from mathematics departments favour the analytical, and that management schools encourage understanding of the context. Presumably, engineers would also tend align with the analytical. However, it seems from Ormerod's experience that the central core competence, manging process, can only be developed through practice; there is no innate competence, instead there are craft skills that have to be developed. Finally, we would certainly agree with the number of authors who point out that an appropriate learning environment is required for progress to be made from novice to expert in PSM use (Ackermann, 2011; Eden \& Ackermann, 2006; Keys, 2006; Mingers, 2011).

\subsection{Pragmatism}

The question of training leads us to further reflections. Do we recommend that engineering organisations train their System Engineers in established PSMs such as SSM, or do we recognise that the proposition $P_{3}$ (Adaptation/Creativity) is in fact something that is likely to be strongly prevalent amongst engineers and needs to be encouraged? The latter is suggested in (Yearworth, Edwards, Davis, Burger, \& Terry, 2013) where this quality of adaptation is reflected in an ad hoc PSM approach coupled with an essential engineering pragmatism. This mirrors Ormerod's argument for pragmatism being "attractive" to OR practitioners (Ormerod, 2006) and Key's observation that adaptation is an essential quality of moving from novice to expert use (Keys, 2006). However, if there is an abundance of pragmatic ad hoc use then the size of the problem for PSM researchers in deciding the truth of $\widehat{P S M}=P S M$ is likely to get worse. However, the point of this paper is to suggest a way forward here.

\subsection{Causal realism and the structure/agency debate}

Causal mechanisms are fundamental and permit us to hold that the task of research is to arrive at (empirically) justified theories and hypotheses about those causal mechanisms. The general nature of the mechanisms that underlie social causation has been the subject of debate. Several broad themes may be identified: agency versus structural theories. Lane attempted to link causality and agency structure issues within a System Dynamics frame (Lane, 1999, 2001a, 2001b). Further understanding we think could be achieved through adopting causal mechanisms, i.e., the causal processes and causal interactions, that provide 
the mechanisms by which the world works; to understand why certain things happen, we need to see how they are produced by these mechanisms.

\subsection{Extension of our work}

Further analysis can be conducted for a number of case studies. In particular we may find that despite the number of possible permutations of the configurations in the analysis, a relatively small number of combinations may account for a relatively large share of all interventions studied. This phenomenon, which is known as limited diversity (e.g. (Ragin, 1987)), presents an important issue. With more cases the situation of limited diversity can be explored by means of the truth table shown in $\$ 9$ - an analytical tool for listing all possible combinations of causal conditions. The truth table lists all the characteristics and if possible one outcome. It would then be possible to identify the conceivable configurations of the intervention characteristics that show empirical instances.

\section{Conclusions}

We have developed a set of testable propositions to address the problem of non-codified PSM use in engineering organisations. This has been motivated by the need to be able to detect PSM use when it has not been described as such so that we enlarge the data set available to us for PSM evaluation and also for PSM development. We have also been motivated by the desire to reinterpret PSM methodology into a set of principles or axioms, which would be valuable in motivating the engineering community to more widely use PSMs and/or formalise existing use of non-codified PSMs in order to fully engage in the necessary activity of methodological improvement.

The process of developing the set of testable propositions led us from an analysis of existing attempts at constitutive definitions for PSMs through a review of the PSM literature. The analysis of three cases studies using our framework led us to a number of reflections about the need for pre-screening to speed up the processes of finding possible PSM use, the nature of expertise in PSM use and the essential pragmatism that must lie behind the important property of adaptation. Underpinning our framework has been an appeal to causal realism as both an ontological basis for our work and a guide to methodology. This is in contrast to the ontological basis on theories of social order and change from Burrell and Morgan, or of the attempt to sidestep these by Checkland in his proposal for an epistemic shift.

We believe that the results from the work presented here can be viewed as an approach to demystifying PSMs by our proposal for a generic constitutive definition. Having arrived at 
this definition we have provided a method for evaluating claims of PSM use, i.e. a method of PSM detection, as a set of testable propositions about practice. This method of PSM detection avoids the difficulties arising from the irregularities associated with the existential question of purpose and specific outcomes of PSM use - these are more properly the concern of PSM evaluation. We have shown how these testable propositions can be used to assess cases of non-codified PSM use in the presentation of the three case studies. The future prospect for our method is that it enables analysis over large numbers of cases of PSM use and this is where our programme of work takes us next.

We recognise that colleagues in the field of PSM research are likely to contest the elements of $[P]$ but we welcome the debate and an opportunity to improve $[P]$ in order to effectively contribute to methodology development. We have started with the thesis that noncodified PSM use is prevalent in engineering organisations because this reflects the selection bias of the authors in the organisations in which they happen to be working. We would expect this thesis to also hold in any other organisation dealing with problem contexts that are roughly $(C P)$. One thing is sure; bringing to the attention of the PSM community more data from non-codified PSM use can only be good.

\section{ACKNOWLEDGEMENTS}

We would like to thank Dr Darren York at Rolls Royce for his help in provision and analysis of the gas turbine engine modification case study. We would also like to thank the referees for their valuable feedback on the first draft of this paper. 


\section{REFERENCES}

Ackermann, F. (2011). Getting "messy" with problems: The challenges of teaching "soft" OR. INFORMS Transactions on Education, 12(1), 55-64.

Ackermann, F. (2012). Problem structuring methods 'in the Dock': Arguing the case for Soft OR. European Journal of Operational Research, 219(3), 652-658. doi: 10.1016/j.ejor.2011.11.014

Ackermann, F., Eden, C., \& Williams, T. (1997). Modeling for litigation: Mixing qualitative and quantitative approaches. Interfaces, 27(2), 48-65. doi: 10.1287/inte.27.2.48

Ackoff, R. L. (1979). Future of Operational-Research is Past. Journal of the Operational Research Society, 30(2), 93-104. doi: 10.2307/3009290

Ackoff, R. L. (1981). The Art And Science Of Mess Management. Interfaces, 11(1), 20-26.

Andersen, D. F., \& Richardson, G. P. (1997). Scripts for group model building. System Dynamics Review, 13(2), 107-129. doi: DOI: 10.1002/(SICI)10991727(199722)13:2<107::AID-SDR120>3.0.CO;2-7

Andersen, D., Vennix, J., Richardson, G., \& Rouwette, E. (2007). Group model building: problem structuring, policy simulation and decision support. Journal of the Operational Research Society, 58(5), 691-694. doi: 10.1057/palgrave.jors.2602339

Bell, S. (2012). DPSIR = A Problem Structuring Method? An exploration from the "Imagine" approach. European Journal of Operational Research, 222(2), 350-360. doi: http://dx.doi.org/10.1016/j.ejor.2012.04.029

Black, J. A., \& Boal, K. B. (1994). Strategic resources - traits, configurations and paths to sustainable competitive advantage. Strategic Management Journal, 15, 131-148.

Buckle-Henning, P., Wilmshurst, J., \& Yearworth, M. (2012). Understanding Systems Thinking: An Agenda for Applied Research in Industry. Paper presented at the 56th Meeting of the International Society for the Systems Sciences, San Jose, USA. http://journals.isss.org/index.php/proceedings56th/article/view/1909

Burrell, G., \& Morgan, G. (1979). Sociological paradigms and organisational analysis : elements of the sociology of corporate life: Ashgate, 1992.

Cabrera, D., Colosi, L., \& Lobdell, C. (2008). Systems thinking. Evaluation and Program Planning, 31(3), 299-310. doi: 10.1016/j.evalprogplan.2007.12.001

Checkland, P., \& Holwell, S. (2004). "Classic" OR and "soft" OR - an asymmetric complementarity. In M. Pidd (Ed.), Systems Modelling: Theory and Practice. Chichester: John Wiley \& Sons, Ltd.

Checkland, P., \& Scholes, J. (1999). Soft Systems Methodology in Action: Including a 30year retrospective. Chichester: Wiley.

Checkland, P.M., \& Jenkins, G.M. (1974). Learning by doing: systems education at Lancaster University. Journal of Systems Engineering, 4(1), 40-51.

CUED. (2011). Soft Systems Methodology. Retrieved 10th December 2012, from http://www.ifm.eng.cam.ac.uk/dstools/control/softsm.html

Dando, M. R., \& Bennett, P. G. (1981). A Kuhnian crisis in management science. Journal of the Operational Research Society, 32(2), 91-103. doi: 10.2307/2581256

Doty, D. H., \& Glick, W. H. (1994). Typologies as a unique form of theory building - toward improved understanding and modeling. Academy of Management Review, 19(2), 230251. doi: $10.2307 / 258704$

Eden, C., \& Ackermann, F. (2006). Where next for problem structuring methods. Journal of the Operational Research Society, 57(7), 766-768. doi: 10.1057/palgrave.jors.2602090

Eisenhardt, K. M. (1989). Building theories from case-study research. Academy of Management Review, 14(4), 532-550. doi: 10.2307/258557 
Giddens, A. (1984). The constitution of society : outline of the theory of structuration. Cambridge: Polity.

Gregory, A., \& Atkins, J. (2012). It looks like a PSM and it does what a PSM does but is it a PSM? Paper presented at the 25th Conference on Operational Research (Euro 2012), Vilnius, Lithuania.

Gregory, A. J., Atkins, J. P., Burdon, D., \& Elliott, M. (2013). A problem structuring method for ecosystem-based management: The DPSIR modelling process. European Journal of Operational Research, 227(3), 558-569. doi: 10.1016/j.ejor.2012.11.020

Hall, J. W., Blockley, D. I., \& Davis, J. P. (1998). Uncertain inference using interval probability theory. International Journal of Approximate Reasoning, 19(3-4), 247264.

Henning, P., \& Chen, W. C. (2012). Systems Thinking: Common Ground or Untapped Territory? Systems Research and Behavioral Science, 29(5), 470-483. doi: $10.1002 /$ sres. 2155

House of Commons Committee of Public Accounts. (2013). The dismantled National Programme for IT in the NHS. (HC294). London: The Stationery Office Limited Retrieved from http://www.publications.parliament.uk/pa/cm201314/cmselect/cmpubacc/294/294.pdf

Jackson, M. C. (1993a). Social-theory and operational-research practice. Journal of the Operational Research Society, 44(6), 563-577. doi: 10.1057/jors.1993.98

Jackson, M. C. (1993b). The System of Systems Methodologies - A Guide to Researchers. Journal of the Operational Research Society, 44(2), 208-209. doi: 10.1057 /jors. 1993.42

Jackson, M. C. (2000). A Systems Approach to Management. New York: Kluwer.

Jackson, M. C. (2001). Critical systems thinking and practice. European Journal of Operational Research, 128(2), 233-244.

Jackson, M. C. (2003). Systems thinking : creative holism for managers. Chichester: John Wiley.

Jackson, M. C., \& Keys, P. (1984). Towards a System of Systems Methodologies. Journal of the Operational Research Society, 35(6), 473-486.

Katz, D., \& Kahn, R.L. (1973). The Social Psychology of Organizations (2nd ed.): John Wiley \& Sons.

Keys, P. (1989). OR as technology - some issues and implications. Journal of the Operational Research Society, 40(9), 753-759. doi: 10.1057/jors.1989.137

Keys, P. (2006). On becoming expert in the use of problem structuring methods. Journal of the Operational Research Society, 57(7), 822-829. doi: 10.1057/palgrave.jors.2602194

Knabb, R.D., Rhome, J.R., \& Brown, D.P. (2005). Tropical Cyclone Report Hurricane Katrina 23-30 August 2005: National Hurricane Center.

Kysar, D. A., \& McGarity, T. O. (2006). Did NEPA drown New Orleans? The levees, the blame game, and the hazards of hindsight. Duke Law Journal, 56(1), 179-235.

Lane, D. C. (1999). Social theory and system dynamics practice. European Journal of Operational Research, 113(3), 501-527. doi: 10.1016/S0377-2217(98)00192-1

Lane, D. C. (2001a). Rerum cognoscere causas: Part I - How do the ideas of system dynamics relate to traditional social theories and the voluntarism/determinism debate? System Dynamics Review, 17(2), 97-118. doi: 10.1002/Sdr.209

Lane, D. C. (2001b). Rerum cognoscere causass. Part II - Opportunities generated by the agency/structure debate and suggestions for clarifying the social theoretic position of system dynamics. System Dynamics Review, 17(4), 293-309. doi: 10.1002/sdr.221 
Little, D. (2011). Causal Mechanisms in the Social Realm. In P. M. Illari, F. Russo \& J. Williamson (Eds.), Causality in the Sciences (pp. 273-316). Oxford: Oxford University Press.

Merton, R.K. (1963). Social Theory and Social Structure. Revised and enlarged edition. (Seventh printing.): pp. xviii. 645. Free Press of Glencoe: [New York,] 1963.

Midgley, G. (1997). Dealing with coercion: Critical Systems Heuristics and beyond. Systems Practice, 10(1), 37-57.

Midgley, G. (2000). Systemic intervention : philosophy, methodology, and practice. New York: Kluwer Academic/Plenum.

Midgley, G., Cavana, R. Y., Brocklesby, J., Foote, J. L., Wood, D. R. R., \& Ahuriri-Driscoll, A. (2013). Towards a new framework for evaluating systemic problem structuring methods. European Journal of Operational Research, 229(1), 143-154. doi: 10.1016/j.ejor.2013.01.047

Miller, L. M. (2012). Controlling disasters: recognising latent goals after Hurricane Katrina. Disasters, 36(1), 122-139. doi: 10.1111/j.1467-7717.2011.01244.x

Mingers, J. (1992). Recent Developments in Critical Management Science. Journal of the Operational Research Society, 43(1), 1-10.

Mingers, J. (2000). The contribution of critical realism as an underpinning philosophy for OR/MS and systems. Journal of the Operational Research Society, 51(11), 12561270. doi: 10.1057/palgrave.jors. 2601033

Mingers, J. (2003). A classification of the philosophical assumptions of management science methods. Journal of the Operational Research Society, 54(6), 559-570. doi: 10.1057 /palgrave.jors. 2601436

Mingers, J. (2007). Operational research: the science of better? Journal of the Operational Research Society, 58(5), 683-686. doi: 10.1057/palgrave.jors.2602333

Mingers, J. (2011). Soft OR comes of age-but not everywhere! Omega-International Journal of Management Science, 39(6), 729-741. doi: 10.1016/j.omega.2011.01.005

Mingers, J., \& Rosenhead, J. (2004). Problem structuring methods in action. European Journal of Operational Research, 152(3), 530-554. doi: 10.1016/s03772217(03)00056-0

Mingers, J., \& Rosenhead, J. (2011). Introduction to the special issue: Teaching soft O.R., problem structuring methods, and multimethodology. INFORMS Transactions on Education, 12(1), 1-3.

Ormerod, R. (201x). Critical rationalism in practice: strategies to manage subjectivity in OR investigations. European Journal of Operational Research(0). doi: http://dx.doi.org/10.1016/j.ejor.2013.12.018

Ormerod, R. (1996). On the nature of OR - Entering the fray. Journal of the Operational Research Society, 47(1), 1-17.

Ormerod, R. (2005). Putting soft OR methods to work: the case of IS strategy development for the UK Parliament. Journal of the Operational Research Society, 56(12), 13791398. doi: 10.1057/palgrave.jors. 2601963

Ormerod, R. (2006). The history and ideas of pragmatism. Journal of the Operational Research Society, 57(8), 892-909. doi: 10.1057/palgrave.jors.2602065

Ormerod, R. (2013a). The mangle of OR practice: towards more informative case studies of 'technical' projects. Journal of the Operational Research Society. doi: doi:10.1057/jors. 2013.78

Ormerod, R. (2013b). OR competences: the demands of problem structuring methods. EURO Journal on Decision Processes, 1-28. doi: 10.1007/s40070-013-0021-6

Parsley, A., York, D., Dunford, C., \& Yearworth, M. (2013, 15-18 April 2013). The use of a systems engineering process guide to accelerate improvement in systems engineering 
application and expertise. Paper presented at the IEEE International Systems Conference (SysCon 2013). doi: 10.1109/SysCon.2013.6549962

Pawson, R. (1989). A measure for measures : a manifesto for empirical sociology. London: Routledge.

Pawson, R., \& Tilley, N. (1997). Realistic Evaluation. London: Sage.

Ragin, C. C. (1987). The comparative method: moving beyond qualitative and quantitative strategies. Berkeley: University of California Press.

Ragin, C. C. (2000). Fuzzy-set social science. Chicago: University of Chicago Press.

Ragin, C. C., \& Pennings, P. (2005). Fuzzy sets and social research. Sociological Methods \& Research, 33(4), 423-430. doi: 10.1177/0049124105274499

Ragin, C. C., \& Strand, S. I. (2008). Using qualitative comparative analysis to study causal order - Comment on Caren and Panofsky (2005). Sociological Methods \& Research, 36(4), 431-441. doi: 10.1177/0049124107313903

Richardson, G. P., \& Andersen, D. F. (1995). Teamwork in Group Model-Building. System Dynamics Review, 11(2), 113-137. doi: 10.1002/sdr.4260110203

Ring, J. (1998). A value-seeking approach to the engineering of systems. Paper presented at the IEEE International Conference on Systems, Man, and Cybernetics. doi: 10.1109/ICSMC.1998.725069

Rittel, H. W. J., \& Webber, M. M. (1973). Dilemmas in a General Theory of Planning. Policy Sciences, 4(2), 155-169.

Rosenhead, J. (1992). Into the Swamp - The Analysis of Social-Issues. Journal of the Operational Research Society, 43(4), 293-305. doi: 10.1057/jors.1992.44

Rosenhead, J. (1996). What's the problem? An introduction to problem structuring methods. Interfaces, 26(6), 117-131. doi: 10.1287/inte.26.6.117

Rosenhead, J. (2006). Past, present and future of problem structuring methods. Journal of the Operational Research Society, 57(7), 759-765. doi: 10.1057/palgrave.jors.2602206

Sattar, A. M. A., Kassem, A. A., \& Chaudhry, M. H. (2008). Case Study: 17th Street Canal Breach Closure Procedures. Journal of Hydraulic Engineering-Asce, 134(11), 15471558. doi: 10.1061/(asce)0733-9429(2008)134:11(1547)

Sayer, A. (1992). Method in social science : a realist approach (2nd ed.). London: Routledge.

Simon, H. A. (1991). Bounded Rationality and Organizational Learning. Organization Science, 2(1), 125-134. doi: 10.2307/2634943

Sterman, J. D. (2002). All models are wrong: reflections on becoming a systems scientist. System Dynamics Review, 18(4), 501-531. doi: 10.1002/sdr.261

Strauss, A. L., \& Corbin, J. (1998). Basics of qualitative research : techniques and procedures for developing grounded theory (2nd ed.). Thousand Oaks ; London ; New Delhi: Sage.

Taket, A., \& White, L. (2000). Partnerships and participation: decision making in a multiagency setting. Chichester: Wiley.

Ulrich, W. (2003). Beyond methodology choice: critical systems thinking as critically systemic discourse. Journal of the Operational Research Society, 54(4), 325-342. doi: 10.1057 /palgrave.jors. 2601518

Ulrich, W., \& Reynolds, M. (2010). Critical Systems Heuristics. New York: Springer.

Vennix, J. (1996). Group Model Building: Facilitating Team Learning Using System Dynamics. Chichester: Wiley.

Vennix, J. (1999). Group model-building: tackling messy problems. System Dynamics Review, 15(4), 379-401.

Warfield, J. N. (1995). Spreadthink - Explaining Ineffective Groups. Systems Research, 12(1), 5-14. doi: 10.1002/sres.3850120104 
Weick, K. E. (2007). The generative properties of richness. Academy of Management Journal, 50(1), 14-19.

White, L. (2006). Evaluating problem-structuring methods: developing an approach to show the value and effectiveness of PSMs. Journal of the Operational Research Society, 57(7), 842-855. doi: 10.1057/palgrave.jors.2602149

White, L. (2009). Understanding problem structuring methods interventions. European Journal of Operational Research, 199(3), 823-833. doi: 10.1016/j.ejor.2009.01.066

Williams, T., Eden, C., Ackermann, F., \& Tait, A. (1995). The Effects of Design Changes and Delays on Project Costs. Journal of the Operational Research Society, 46(7), 809-818. doi: 10.1057/jors.1995.114

Yearworth, M, Dunford, C.N., York, D.M., \& Godfrey, P. (2012). Critical Awareness of Worldviews in Organisational Change. Paper presented at the 25th Conference on Operational Research (Euro 2012), Vilnius, Lithuania.

Yearworth, M, \& Edwards, G. (2013). On the Desirability of Integrating Research Methods into Overall Systems Approaches in the Training of Engineers: Analysis Using SSM. Systems Research and Behavioral Science. doi: 10.1002/sres.2167

Yearworth, M., Edwards, G., Davis, J., Burger, K., \& Terry, A. (2013). Integrating Problem Solving and Research Methods Teaching for Systems. Paper presented at the 11th Annual Conference on Systems Engineering Research (CSER 2013), Atlanta, GA. USA. doi: 10.1016/j.procs.2013.01.113

Yearworth, M., \& White, L. (2013). The uses of qualitative data in multimethodology: Developing causal loop diagrams during the coding process. European Journal of Operational Research, 231(1), 151-161. doi: 10.1016/j.ejor.2013.05.002

Zhu, Z. (2011). After paradim: why mixing-methodology theorising fails and how to make it work again. Journal of the Operational Research Society, 62(4), 784-798. doi: 10.1057/jors.2010.31 


\section{APPENDIX 1. CONCEPTS ELICITED THROUGH GROUNDED ANALYSIS OF THE PSM REVIEW}

\section{LITERATURE}

\begin{tabular}{|c|c|c|c|c|c|c|c|c|c|c|c|c|}
\hline 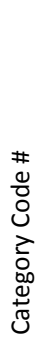 & Category & 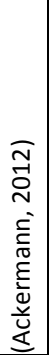 & 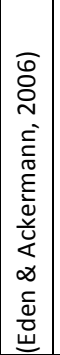 & 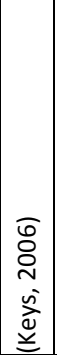 & 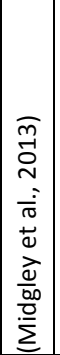 & 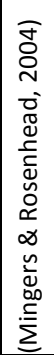 & 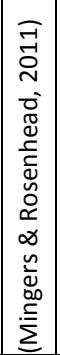 & 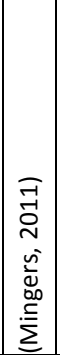 & 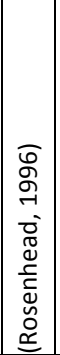 & 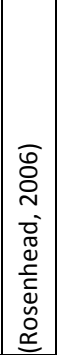 & 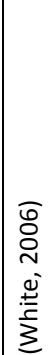 & 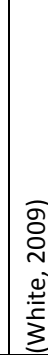 \\
\hline 0 & Towards A Constitutive Definition of PSMs & & & & & & & & & & & \\
\hline 1 & Characteristics of PSMs & & & & & & 1 & & 1 & & & \\
\hline 2 & As opposed to standard OR methods & & & & & & & 2 & 1 & 3 & & \\
\hline 3 & approaches are complementary & & & & & & 1 & & & & & \\
\hline 4 & Dissatisfaction with traditional mathematical methods of OR & & & & & & 1 & & & & & \\
\hline 5 & $\begin{array}{l}\text { However, the limitations of purely mathematical OR methods } \\
\text { became apparent during the } 1960 \text { s and } 1970 \text { s" }^{\prime \prime}\end{array}$ & & & & & & & 1 & & & & \\
\hline 6 & Improvements, not solutions. Partial or local improvements & & & & & 1 & & & & & & \\
\hline 7 & Managerialism & & & & & & & & & 1 & & \\
\hline 8 & mathematically sophisticated but contextually naïve" & 1 & & & & & & & & & & \\
\hline 9 & Multiple perspectives, need to explore, no optimization & & 2 & & & & & & 2 & & & \\
\hline 10 & $\begin{array}{l}\text { Operations Research and Management Science, these journals } \\
\text { essentially limit OR" }\end{array}$ & & & & & & & 1 & & & & \\
\hline 11 & Optimization+Objectivity=Opt Out & & & & & & & 1 & & & & \\
\hline 12 & Scenarios not forecasts & & & & & & & & 2 & & & \\
\hline 13 & soft O.R., has a less clear meaning & & & & & & 1 & & & & & \\
\hline 14 & Structuring, not solving & & 2 & & & & & & 1 & & & \\
\hline 15 & Subjectivity not objective advice & & & & & 1 & & & & & & \\
\hline 16 & Supporting judgement, not representing it & & & & & & & & 2 & & & \\
\hline 17 & Attributes & & & & & & & & 1 & & & \\
\hline 18 & 2nd order typifications & & & & & & & & & & & 1 \\
\hline 19 & Action research & 1 & 1 & & & & & & & 1 & & \\
\hline 20 & Active development & & & & & 1 & & & & & & \\
\hline 21 & aka Soft OR & 2 & & & & & & & & & & \\
\hline 22 & being able to look at the big picture & 1 & & & & & & & & & & \\
\hline 23 & Complex interventions seeking change at many levels & & & & & & & & & & 1 & \\
\hline 24 & Complex technology for dealing with wicked problems & & & & & & & & & & 1 & \\
\hline 25 & Contingent solutions & & & & & & & & & & 1 & \\
\hline 26 & Design approach & 1 & & & & & & & & & & \\
\hline 27 & Developing methodology & & & & & & & & & 1 & & \\
\hline 28 & enabling new options to emerge & 1 & & & & & & & & & & \\
\hline 29 & ensuring the situation is explored from a range of perspectives & 1 & & & & & & & & & & \\
\hline 30 & exploration, learning and commitment rather than optimization & & & & & & & 1 & & & & \\
\hline 31 & Family of methods & & & & & & & & 1 & & 1 & \\
\hline 32 & Functions through interaction and iteration & & & & & & & & 1 & 1 & & \\
\hline 33 & History of use & & & & & & & & & 2 & & \\
\hline 34 & intelligence, design, evaluation and implementation - Simon 1976 & 1 & & & & & & & & & & \\
\hline 35 & $\begin{array}{l}\text { Intervention - systematic or purposeful action by an agent to create } \\
\text { change or improvements }\end{array}$ & & & & & & & & & & & 4 \\
\hline 36 & Irreducible uncertainties & & & & & 1 & & & & & & \\
\hline 37 & Layered approach & & & & & 1 & & & & & & \\
\hline 38 & Limited quantification & & & & & & & & 1 & 1 & & \\
\hline 39 & Loosely articulated processes & & & & & & & & 1 & & & \\
\hline 40 & Managing complexity & 1 & & & & & & & & & & \\
\hline 41 & $\begin{array}{l}\text { new problem structuring methods are being produced on a regular } \\
\text { basis, }\end{array}$ & & & & 1 & & & & & & & \\
\hline 42 & Not mathematical & & & & & & & 1 & & & & \\
\hline 43 & Options & & & & & 1 & & & 3 & & & \\
\hline 44 & Participative methods & & & & 1 & & & & & & & \\
\hline 45 & Possible actions & & & & & 1 & & & 1 & & & \\
\hline 46 & Problem of simplification & & 1 & & & & & & & & & \\
\hline 47 & Relevant possibilities for action not probabilities & & & & & & & & 1 & & & \\
\hline 48 & Restricted mathematization & & & & & & & & 1 & & & \\
\hline 49 & Rudimentary statistics, mathematics & & & & & 1 & & & & & & \\
\hline 50 & Significant uncertainty is expected and tolerated & & & & & & & 1 & & & & \\
\hline 51 & Social requirements of method have technical implications & & & & & & & & 1 & & & \\
\hline
\end{tabular}




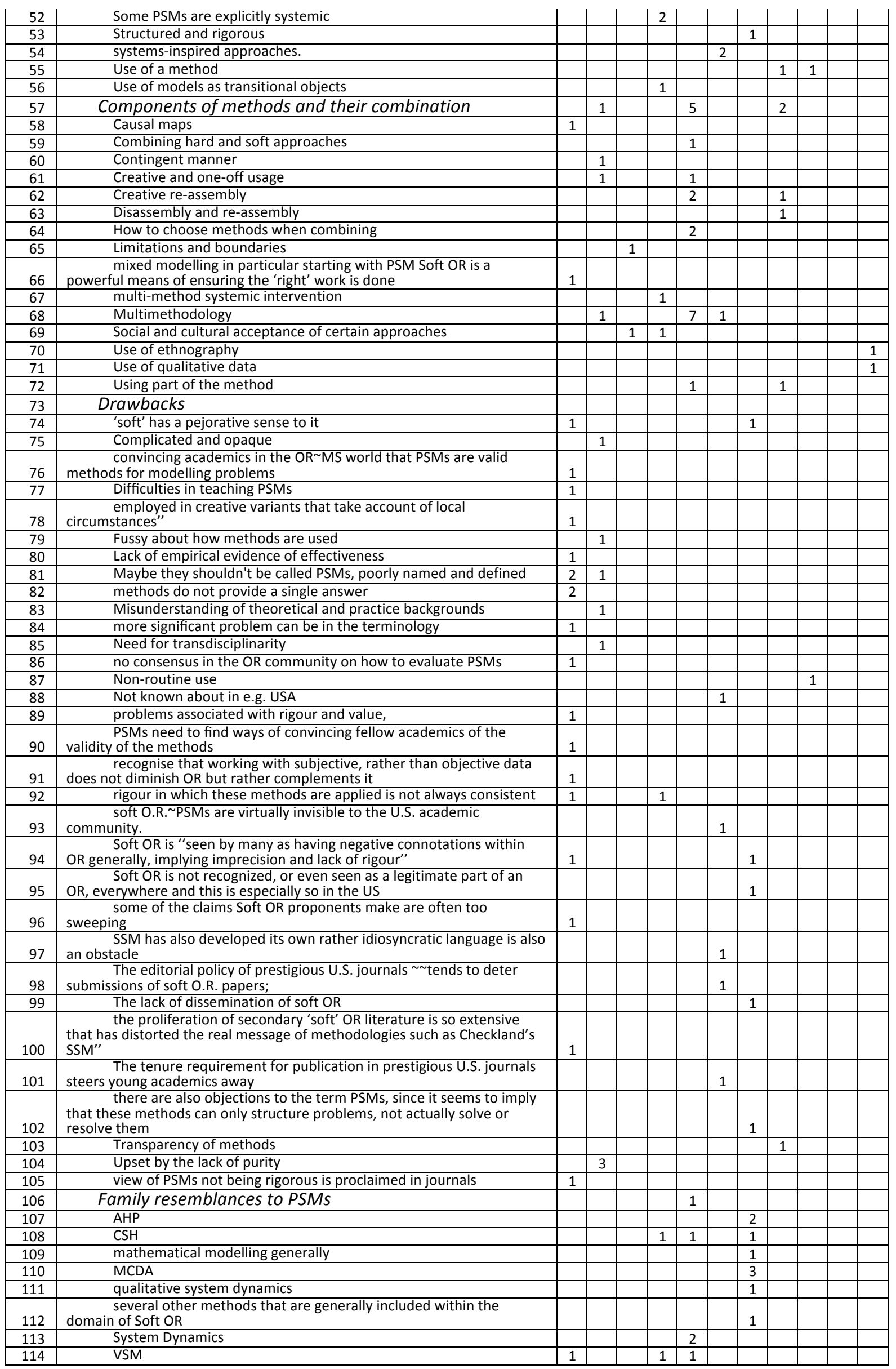




\begin{tabular}{|c|c|c|c|c|c|c|c|c|c|c|c|c|}
\hline 115 & Group work & & & & 1 & 1 & & & 2 & 1 & & \\
\hline 116 & Commitment of group & & & & & & & & 1 & & & \\
\hline 117 & Conflict & 2 & & & 2 & 1 & & 1 & & 3 & 3 & 1 \\
\hline 118 & Facilitation & & 1 & & & & & & 1 & & & \\
\hline 119 & Accommodates multiple alternate perspectives & & & & & & & & 1 & 1 & & \\
\hline 120 & $\begin{array}{l}\text { a 'common understanding' does not necessarily imply } \\
\text { consensus or agreement across the board }\end{array}$ & & & & 1 & & & & & & & \\
\hline 121 & Achieving consensus, brokerage (maybe merge with mediation) & 3 & 1 & & & 2 & 2 & & & 2 & 1 & 2 \\
\hline 122 & agreements that would and could be implemented & 1 & & & 1 & & & & & & & \\
\hline 123 & Being an expert PSM user & & 1 & 2 & & & & & & & & \\
\hline 124 & Disinterested or neutral role & & & & & 1 & & & & & & 1 \\
\hline 125 & Largely abandoned as a concept & & & & & & & & & & & 1 \\
\hline 126 & Effective model building & & 1 & & & & & 1 & & & & \\
\hline 127 & Elicit relevant knowledge and reflect back in a structured form & & & & & 3 & & & 1 & & & \\
\hline 128 & Enable perspectives to be brought together & 3 & & & & 1 & & 1 & & & & 1 \\
\hline 129 & Familiar tasks & & & 1 & & & & & & & & \\
\hline 130 & Generates ownership of problem formulation and actions & 1 & & & & 1 & & & 1 & 1 & & \\
\hline 131 & Manage content and process & 2 & & & & & & & & & & \\
\hline 132 & Managing interpersonal processes and dynamics of a group & & & & & 1 & & & 1 & & & 1 \\
\hline 133 & Managing partnerships & & & & & & & & & & 1 & \\
\hline 134 & Mediation - reaching agreement (maybe merge with consensus) & 3 & 2 & & & & 1 & & & 2 & 2 & \\
\hline 135 & Moving forward between stages & & 2 & & & 1 & & & & & 1 & \\
\hline 136 & or more fluid non-linear approaches & & & & & & & & & & & 1 \\
\hline 137 & Relationship building & & & & & & & & & & 1 & 1 \\
\hline 138 & Coalition building & & & & & & & & & & & 1 \\
\hline 139 & Enrolment strategies & & & & 2 & & & & & & & 1 \\
\hline 140 & Reciprocity & & & & & & & & & & & 1 \\
\hline 141 & $\begin{array}{l}\text { researcher becomes an interactive part of the situation in which } \\
\text { he or she is seeking to intervene using systemic PSMs }\end{array}$ & & & & 1 & & & & & & & \\
\hline 142 & Role of facilitator & & & & & 1 & & & 2 & & & \\
\hline 143 & Multiple actors & & & & & & & 1 & & 1 & & \\
\hline 144 & Physical arrangements & & & & & 1 & & & & & & \\
\hline 145 & Stakeholders, multiple actors & 3 & 1 & & 9 & 3 & 2 & & 1 & 2 & 4 & \\
\hline 146 & Taking responsibility for actions & 1 & & & & & & & & 2 & & \\
\hline 147 & Workshops & & & & 1 & $\begin{array}{l}1 \\
1\end{array}$ & & 1 & 1 & & & \\
\hline 148 & Workshop arrangements and processes & & & & & 1 & & & & & & \\
\hline 149 & Enrolment & & & & & & & & & & & 1 \\
\hline 150 & Interessement & & & & & & & & & & & 1 \\
\hline 151 & Mobilisation of allies & & & & & & & & & & & 1 \\
\hline 152 & Problemitisation & & & & & & & & & & & 1 \\
\hline 153 & Workshop sessions - more than one & & & & & & & & 1 & & & \\
\hline 154 & Worldviews, differing perspectives & 7 & 1 & & 6 & 1 & 2 & 3 & 1 & 3 & 2 & \\
\hline 155 & $\begin{array}{l}\text { Similarities across PSMs - an idea that these are driving } \\
\text { success }\end{array}$ & & 3 & & & & & & & & & \\
\hline 156 & Increasing productivity of group processes & & 1 & & & & & & & & & \\
\hline 157 & Paying attention to the facilitation of effective group processes & & 2 & & & & & & & & & \\
\hline 158 & Significance of facilitation skills & & 1 & & & & & & & & & \\
\hline 159 & Underlying principles (as an open question still) & & 1 & & & & & & & & & \\
\hline 160 & Use of a model as a transitional object & & 1 & & & & & & & & & \\
\hline 161 & Stages & & & & & 8 & & & 1 & & & \\
\hline 162 & Intermediate stage & & & & & & & & 1 & & & \\
\hline 163 & Operate iteratively, cyclical approach & 2 & & & & 1 & & & & 1 & & \\
\hline 164 & Problem formulation & & & & & & & & 1 & & & \\
\hline 165 & Shaping & & & & & & & & 1 & & & \\
\hline 166 & shaping, designing, comparing, and choosing & 1 & & & & & & & & & & \\
\hline 167 & Taking action, actions to improve the situation & 2 & & & & 6 & & & 1 & & & \\
\hline 168 & culturally feasible & 1 & & & & & & & & & & \\
\hline 169 & Resource limitations & & & & 1 & & & & & & & \\
\hline 170 & Systemic enablers & & & & 1 & & & & & & & \\
\hline 171 & systemically desirable & 1 & & & & & & & & & & \\
\hline 172 & Systems community view & 1 & & & & & & & & & & \\
\hline 173 & Types of PSM & & & & & & & 1 & 1 & 1 & & \\
\hline 174 & Causal Loop Diagramming & & & & 1 & & & & & & & \\
\hline 175 & Decision Conferencing & & & & & 2 & & & & & & \\
\hline 176 & Drama theory & 1 & & & & 1 & 1 & 2 & & & 1 & \\
\hline 177 & Interactive Planning & & & & 1 & 1 & 1 & 1 & 1 & & & \\
\hline 178 & Metagame analysis & & & & & & & 2 & 1 & & & \\
\hline 179 & Robustness analysis & 1 & & & & 1 & 1 & 1 & 1 & & & \\
\hline 180 & SAST & & & & 1 & & 1 & 1 & 1 & & & \\
\hline 181 & SCA & 2 & 1 & & & 5 & 1 & 3 & 1 & & 1 & \\
\hline 182 & Choosing mode & & & & & & 1 & 1 & & & & \\
\hline 183 & Comparing mode & & & & & & & 1 & & & & \\
\hline 184 & Designing mode & & & & & & 2 & 1 & & & & \\
\hline 185 & Shaping mode & & & & & & 1 & 1 & & & & \\
\hline
\end{tabular}


Six systemic PSMs (soft systems methodology; interactive planning; causal loop diagramming; viable system diagnosis; critical systems heuristics; and strategic assumption surfacing and testing SODA

188 areas they should spend time developing causal links thought to exist between those concepts, are elicited in individual interviews

190 Conflicts

191 decision areas associated with the situation decision areas, options for managing each area are considered determine the level of urgency and importance maps are subsequently merged into a single "strategic map." Monitor progress of the strategy and gain organizational learning related areas Surface the emergent strategy of the organization in terms of strategic issues, aspirations and taken-for-granted beliefs This strategic map provides the framework for facilitated

216

$217 \quad$ Standard PSM techniques

$218 \quad$ Viable System Diagnosis

219 Use of diagrammatic form of knowledge (aka models)

$220 \quad$ Boundary object

$221 \quad$ Can be used as structure for guiding more numerical modelling

$222 \quad$ Cognitive accessibility by participants

decoupling allows for participants to change their mind without

Contexts for using PSMs - the nature of swamps, messes,

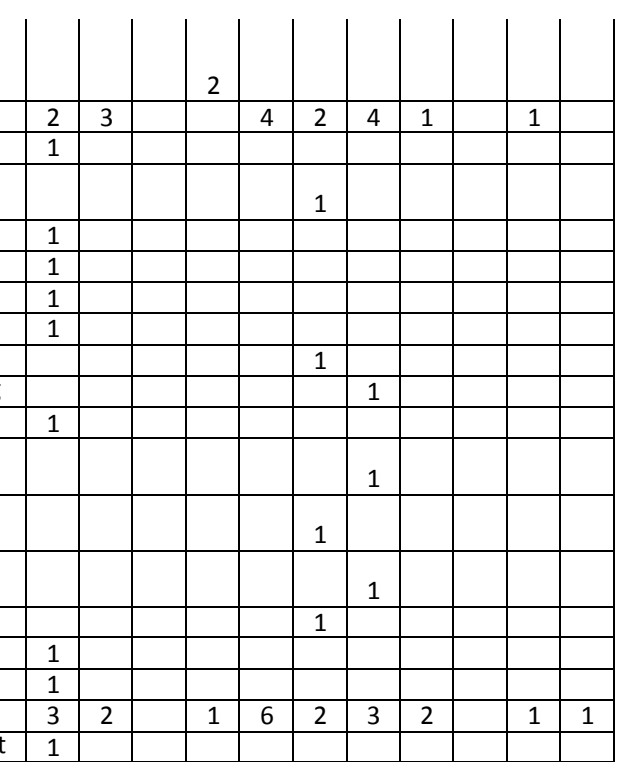

\begin{tabular}{|l|} 
\\
\end{tabular}




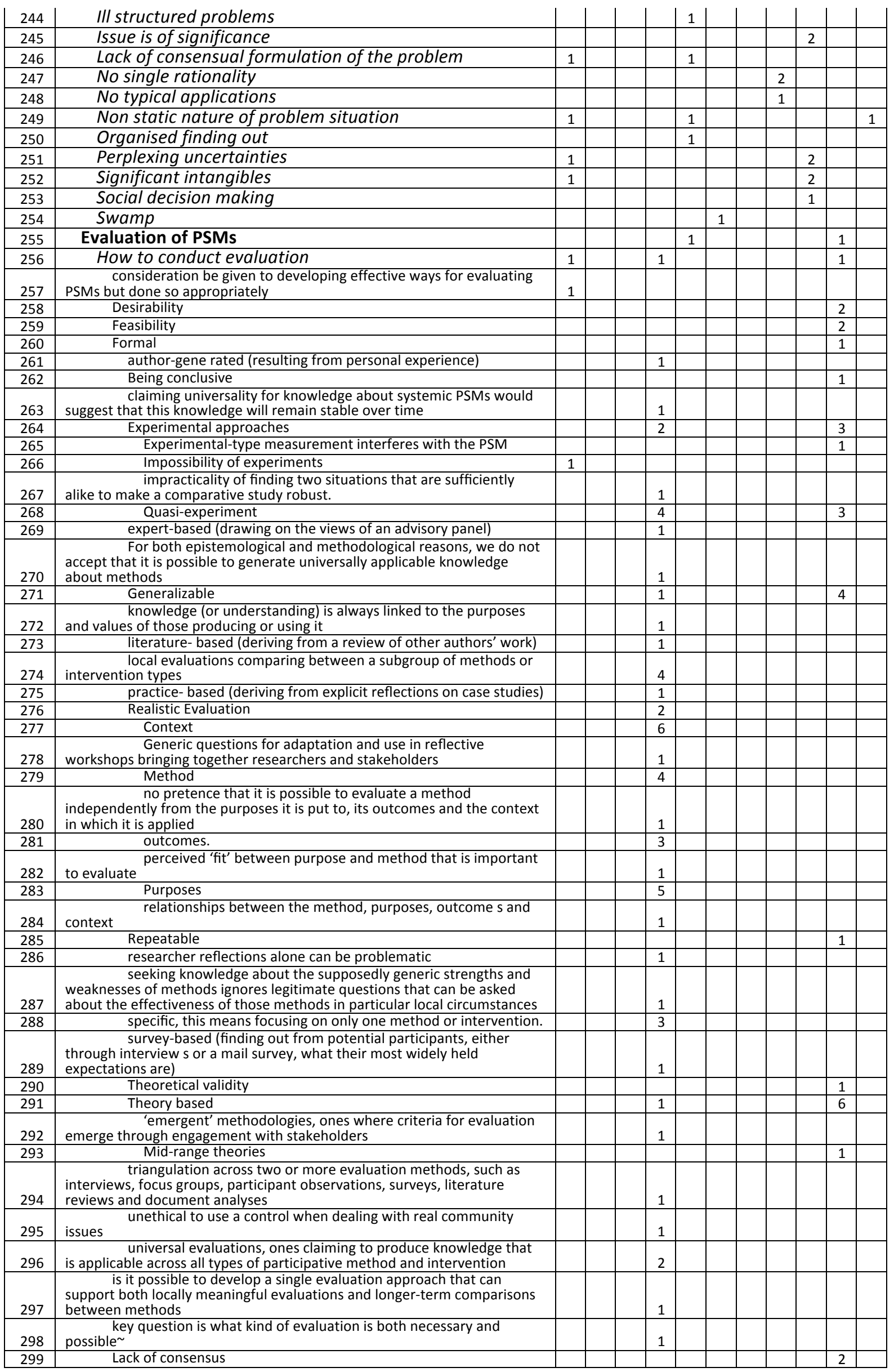


\begin{tabular}{c|c} 
post- intervention debriefings or interviews with project \\
300 & $\begin{array}{c}\text { participants } \\
\text { Questionnaires, pre- post- interviews }\end{array}$
\end{tabular}

\begin{tabular}{c|c} 
post- intervention debriefings or interviews with project \\
300 & participants \\
\hline 301 & Questionnaires, pre- post- interviews
\end{tabular}

302 interventions undertaken by different people

303 Measuring Success

based on explicit criteria reflecting the researcher's experience,

given theory, a literature review andor stakeholder expectations generated

304 through a consultative exercise

305 Clear success criteria

$306 \quad$ Coding and analysing data

$307 \quad$ Collecting data

$308 \quad$ Confounding effects

$309 \quad$ Efficacy can be established through accumulation of evidence

310 It is necessary to distinguish outcome criteria from process criteria

311 Limited scope

$312 \quad$ Longitudinal studies

$313 \quad$ Not possible to measure meaningfully

\begin{tabular}{|c|c} 
quantitatively compared broad classes of methods using a standard \\
314 & set of variables \\
\hline 315 & Real world lived experience
\end{tabular}

use of standard criteria for com- paring methods is therefore made

316 problematic by the need to consider what is unique in each intervention

\begin{tabular}{l|l}
317 & Weak evidence \\
318 & Purpose of evaluation
\end{tabular}

$319 \quad$ Evaluating effectiveness

$320 \quad$ Is it better than doing nothin

$321 \quad$ Is one method better than another

$322 \quad$ Leading to improvement in PSMs

$323 \quad$ Leading to increased uptake in PSM use

$324 \quad$ Providing explanation about an intervention

325 Issues confronting practitioners using PSMs

Anxieties

Attention to detail in workshops

balance has to be struck between rigour and relevance

Becoming an expert in PSM use

Experience leading to effective use, or perceived as successful

Gaining insights for practical learning

$332 \quad$ Infrastructure to support learning

$333 \quad$ Age profile of key originators

In an academic climate characterized by competitive evaluation

of research output, faculty posts are vulnerable to the higher publication

rate possible in traditional $O R_{,}$

335

336

337

discover how the conditic

Training in PSMs

Achieving expert status

subject matter.

338

339

answer

experiential learning is the basis of the teaching approach

extra work having to teach facilitation as well as the methods giving students' confidence in not having to have the 'right'

helping students appreciate the implications of the socio-political

world on the implementation of any recommendation

helping students manage complexity, uncertainty, and holism

342

343

344

345

346

347

348

349

350

351

352

353

354

355

356

357

358

359

360

361

362

and expertise

involvement in "real" learning situations

meaningful learning

Moving from novice to expert

Developing a personal modelling style

Engaging in a complex process of knowledge acquisition

Learning to be adaptable, combining methods, variations

Working at the margins, encountering difficulties

What does it mean to be expert

Modelling expert behaviours

Knowledge as the basis for expertise

Relationship between knowledge and expertise

Theoretical view based on ANT

Types of knowledge, forms of embodiment, actor networks,

Buy-in from stakeholders

Client system

Improving PSMs

Methodology development requires codification and

documentation

Reflecting on PSM use

Strengths

Managing relationships with clients

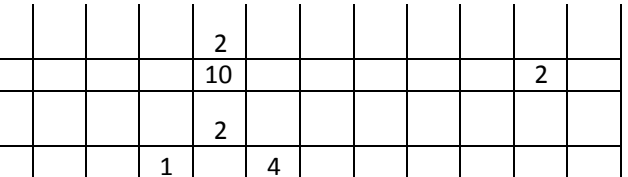

\begin{tabular}{l|l|l|l|} 
& & & \\
\hline
\end{tabular}

\begin{tabular}{|l|l|l|l|l|l|l}
1 & & & & & & \\
\hline
\end{tabular}

\begin{tabular}{ll|l|l|l|}
\hline & & & 1 & \\
\hline 1 & & & 1 & \\
\hline
\end{tabular}

\begin{tabular}{|l|l|l|l|l|}
\hline & & & & 1 \\
\hline
\end{tabular}

\begin{tabular}{|l|l}
\hline 1 & \\
\hline 1 & \\
\hline 3 & \\
\hline
\end{tabular}

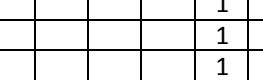

\begin{tabular}{|l|l|l|l|l} 
& & & 3 \\
\hline & & & 2 \\
\hline
\end{tabular}

3

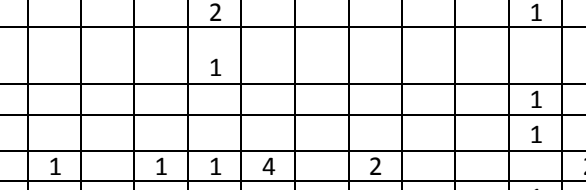

\begin{tabular}{ll|l|l|l|l|}
\hline & & & & 1 \\
\hline
\end{tabular}

\begin{tabular}{llll|l|l|l|l|l|l|l|}
\hline & & & & & & & & & 1 & \\
\hline
\end{tabular}




\begin{tabular}{|c|c|c|c|c|c|c|c|c|c|c|c|c|}
\hline 364 & Negotiating entry & & & & & 1 & & & & & & \\
\hline 365 & Power, dealing with issues arising from (and politics too) & 2 & 3 & & & & & & & & 2 & \\
\hline 366 & Institutional analysis & & & & 1 & & & & & & & \\
\hline 367 & Restrictions from logistics & & & & & 1 & & & & & & \\
\hline 368 & Robustness of outputs & 2 & & & & & & & & & & \\
\hline 369 & Selection of appropriate method & & & 1 & 1 & 3 & & & 1 & & & \\
\hline 370 & Is this tacit or can it be made explicit & & & 1 & & & & & & & & \\
\hline 371 & Selection of workshop members & & & & & 1 & & & & & 2 & \\
\hline 372 & $\begin{array}{l}\text { the importance of publications in the top journals is } \\
\text { clear for without this its status and validity will remain } \\
\text { questionable }\end{array}$ & & & & & & & 1 & & & & \\
\hline 373 & Transferring outputs to non participants & & & & & 1 & & & & 1 & 1 & \\
\hline 374 & Trust & & & & 1 & 1 & & & & & 2 & \\
\hline 375 & Unpredictability of outputs & 1 & & & & & & & & 1 & & \\
\hline 376 & $\begin{array}{l}\text { Theoretical basis of PSMs and their analysis and } \\
\text { evaluation }\end{array}$ & 1 & & 1 & & 2 & & & & & & \\
\hline 377 & Actant Analysis & & & & & & & & & & & 2 \\
\hline 378 & Actor Network Theory & & & & & & & & & & & 5 \\
\hline 379 & Boundary critique & & & & 3 & & & & & & & \\
\hline 380 & Emancipatory and critical approaches & & & & & & & & & & & 1 \\
\hline 381 & Interpretivist view & & 1 & & 2 & 2 & & & & & 7 & \\
\hline 382 & Narrative Theory & & & & & & & & & & & 9 \\
\hline 383 & Narrative & & & & & & & & & & & 2 \\
\hline 384 & Objectivity & & & & 2 & & & 1 & & & & 1 \\
\hline 385 & Positivist view & & & & & 1 & & & & & 4 & 2 \\
\hline 386 & Postmodernism & & & & & & & & & 1 & & \\
\hline 387 & Pragmatism & & & & 2 & 1 & & & & & 3 & \\
\hline 388 & Qualitative & & & & 2 & & & & & & & \\
\hline 389 & Quantitative & & & & 4 & & & & & & & \\
\hline 390 & Realist & & & & & & & & & & 3 & \\
\hline 391 & Social constructivism & & 1 & & & & & & & & 1 & 2 \\
\hline 392 & Sociology of Scientific Knowledge & & & & & & & & & & & 2 \\
\hline 393 & Soft Hard characterisation & & & & & & 1 & 1 & & & & \\
\hline 394 & Subjectivity & 2 & & & 2 & & & & & 2 & & \\
\hline 395 & Technological determinism & & & & & & & & & & & 2 \\
\hline 396 & Theories-in-use in terms of PSM interventions & & & & & & & & & & 1 & \\
\hline
\end{tabular}

Note that the numbers in the cells refer to the number of times the category is coded in each source document. 